\title{
Retrospective Analysis on Antimicrobial Resistance Trends and Prevalence of $\beta$-lactamases in Escherichia coli and ESKAPE Pathogens Isolated from Arabian Patients during 2000-2020
}

\author{
Mahfouz Nasser ${ }^{1,2}$ (D), Snehal Palwe ${ }^{3}$, Ram Naresh Bhargava ${ }^{4}$, Marc G. J. Feuilloley ${ }^{5, *(\mathbb{D})}$ and \\ Arun S. Kharat ${ }^{6, *(1)}$ \\ 1 Department of Biotechnology, Dr. Babasaheb Ambedkar Marathwada University, Sub-Campus, \\ Osmanabad 413 528, India; mahfouznasser@yahoo.com \\ 2 National Center for Public Health Laboratories, Hodeidah, Yemen \\ 3 Department of Environmental Science, S. B. College of Science, Aurangabad 431001, India; \\ snehalpalwe7@gmail.com \\ 4 Department of Microbiology, Babasaheb Bhimrao Ambedkar University, Lucknow 226025, India; \\ bharagavarnbbau11@gmail.com \\ 5 Laboratory of Microbiology Signals and Microenvironments, LMSM EA 4312, University of Rouen, \\ Normandy, F-27000 Evreux, France \\ 6 Laboratory of Applied Microbiology, School of Life Sciences, Jawaharlal Nehru University, \\ New Mehrauli Road, New Delhi 110067, India \\ * Correspondence: marc.feuilloley@univ-rouen.fr (M.G.J.F.); arunkharat2007@gmail.com (A.S.K.)
}

Received: 24 September 2020; Accepted: 19 October 2020; Published: 21 October 2020

\begin{abstract}
The production of diverse and extended spectrum $\beta$-lactamases among Escherichia coli and ESKAPE pathogens is a growing threat to clinicians and public health. We aim to provide a comprehensive analysis of evolving trends of antimicrobial resistance and $\beta$-lactamases among E. coli and ESKAPE pathogens (Enterococcus faecium, Staphylococcus aureus, Klebsiella pneumoniae, Acine to bacter baumannii, Pseudomonas aeruginosa, and Enterobacter species) in the Arabian region. A systematic review was conducted in Medline PubMed on papers published between January 2000 and February 2020 on countries in the Arab region showing different antibiotic resistance among E. coli and ESKAPE pathogens. A total of $n=119,144$ clinical isolates were evaluated for antimicrobial resistance in 19 Arab countries. Among these clinical isolates, 74,039 belonged to E. coli and ESKAPE pathogen. Distribution of antibiotic resistance among E. coli and ESKAPE pathogens indicated that E. coli $(n=32,038)$ was the predominant pathogen followed by K. pneumoniae $(n=17,128)$, P. aeruginosa $(n=11,074)$, methicillin-resistant $S$. aureus (MRSA, $n=4370)$, A. baumannii $(n=3485)$ and Enterobacter spp. $(n=1574)$. There were no reports demonstrating Enterococcus faecium producing $\beta$-lactamase. Analyses revealed 19 out of 22 countries reported occurrence of ESBL (Extended-Spectrum $\beta$-Lactamase) producing E. coli and ESKAPE pathogens. The present study showed significantly increased resistance rates to various antimicrobial agents over the last 20 years; for instance, cephalosporin resistance increased from 37 to $89.5 \%$, fluoroquinolones from 46.8 to $70.3 \%$, aminoglycosides from 40.2 to $64.4 \%$, mono-bactams from 30.6 to $73.6 \%$ and carbapenems from 30.5 to $64.4 \%$. An average of $36.9 \%$ of the total isolates were reported to have ESBL phenotype during 2000 to 2020. Molecular analyses showed that among ESBLs and Class A and Class D $\beta$-lactamases, $b l a_{\mathrm{CTX}-\mathrm{M}}$ and $b l a_{\mathrm{OXA}}$ have higher prevalence rates of $57 \%$ and $52.7 \%$, respectively. Among Class B $\beta$-lactamases, few incidences of $b l a_{\mathrm{VIM}} 27.7 \%$ and $b l a_{\mathrm{NDM}} 26.3 \%$ were encountered in the Arab region. Conclusion: This review highlights a significant increase in resistance to various classes of antibiotics, including cephalosporins, $\beta$-lactam and $\beta$-lactamase inhibitor combinations, carbapenems, aminoglycosides and quinolones among E. coli and ESKAPE pathogens in the Arab region.
\end{abstract}


Keywords: ESBL; E. coli; ESKAPE pathogens; antibiotic resistance; $\beta$-lactamase; Arab region

\section{Introduction}

Before the discovery of penicillin by Alexander Fleming in 1928, infectious diseases accounted for high morbidity and mortality worldwide [1]. After a decade of antibiotic discovery, they were made available for the effective treatment of various bacterial diseases and although the United States Surgeon General at that time, Dr. Stewart, never stated that it was time to close the book on infections, the fraternity of clinicians started thinking that they had won the battle against infectious diseases [2]. However, the inactivation of these antibiotics by bacterial pathogens due to expression of various enzymatic and non-enzymatic resistance mechanisms started appearing within a few years after their introduction in to the market and their subsequent clinical usage [3]. During 1940-1970, diverse classes of antibiotics inhibiting various essential bacterial targets such as DNA, ribosome, peptidoglycan synthesis were introduced, mainly providing antibacterial activity against Gram-positive pathogens, especially Staphylococcus aureus and streptococci [4]. During the same period, $\beta$-lactams, aminoglycosides and quinolines were discovered and predominantly used in treatment of infections caused by staphylococci and streptococci.

Among these three classes of antibiotics, $\beta$-lactams were the mainstay of therapy owing to their well-established clinical safety and efficacy. However, in early 1975, Neu (1975) documented that infections caused by Gram-negative pathogens had started to become more prevalent over Gram-positive infections, which were predominantly community bacterial infections with plenty of therapeutic options available for treatment [5]. With narrow spectrum activity of these old antibiotics, Gram-negative infections associated with Escherichia coli, Klebsiella pneumoniae and Enterobacter spp. began to rise, and bacterial infections shifted from community to hospitals. However, limited therapeutic options were available for the treatment of these nosocomial infections, compelling clinicians to use available therapeutic options with compromised Gram-negative efficacy. This was the era of selection and dissemination of various $\beta$-lactamases including inhibitor resistant $\beta$-lactamases in etiologically prevalent organisms such as E. coli, K. pneumoniae and Enterobacter.

On the other hand, the incidence of infections caused by other Gram-negative opportunistic pathogens such as Pseudomonas aeruginosa and Acine to bacter baumannii in hospital acquired bacterial pneumonia and Ventilator Associated-bacterial Pneumonia (VAP) further complicated the treatment, thus challenging treatment options. Therefore, post 1970, various structural modifications in $\beta$-lactam antibiotics led to the discovery of 3rd- and 4th-generation cephalosporins and carbapenems, which possessed broad spectrum activity encompassing these pathogens. These clinically significant pathogens belonged to E. coli and ESKAPE pathogens. The ability of E. coli and ESKAPE pathogens to acquire and disseminate various resistance genes led to Multiple-Drug Resistance (MDR). There are six nosocomial pathogens in the acronym ESKAPE: Enterococcus faecium, Staphylococcus aureus, Klebsiella pneumoniae, Acine to bacter baumannii, Pseudomonas aeruginosa and Enterobacter spp. [6]. Globally, nosocomial infections caused by MDR E. coli and ESKAPE pathogens are associated with the highest death risk and incur huge treatment costs [7]. Various regulatory agencies such as the US Centers for Disease Control and Prevention (CDC), European Centre for Disease Prevention and Control (ECDC) and the World Health Organization (WHO) have provided detailed information on the antibiotic susceptibility of contemporary susceptible and resistant ESKAPE pathogens based on various surveillance studies. According to a WHO report, at least 700,000 people die each year, and it is estimated that drug-resistance could cause 10 million deaths each year by 2050, with a significant socio-economic impact [8]. Due to globalization, systematic analysis of E. coli strains expressing $\beta$-lactamases and spread of antibiotic resistance traits among ESKAPE pathogens from both developed and developing countries is of paramount importance.

Such systematic surveillance data is not available for various developing countries such as Africa, the Middle East, and European countries outside the European Union [9]. Only limited data are available for even the Arab regions, which is a geographical term for the countries located between 
two continents: Asia and Africa. These Arab regions comprise twenty-two countries, twelve of which are located in western Asia, while ten are in northern Africa. Herein, we performed an extensive literature survey covering the period from January 2000 to February 2020 and the antibiotic resistance trends among E. coli and ESKAPE pathogens from the 22 countries of the Arab region. Based on the available data, phenotypic and genotypic expression of various $\beta$-lactamase traits were highlighted country-wise. As per the methodological standards outlined for the conduct of PRISMA Intervention review, we divided the study period (2000-2020) into four Sub-groups; 2000-2005, 2006-2010, 2011-2015, and 2016-2020 and then compared and analyzed antibiotic resistance trends between these periods.

\section{Materials and Methods}

Various studies showing activity of different classes of antibiotics against E. coli and ESKAPE pathogens, published between January 2000 to February 2020 in Medline PubMed databases, were reviewed. We followed the Methodological Standards guidelines for the Conduct of PRIMSA Intervention Review to study the antibiotic resistance trends over 20 years within 19 Arab countries [10] (see Figure 1). We performed a systematic review of the available literature on specific antimicrobial resistance data, primarily for Arab countries for which no systematic surveillance data on antimicrobial resistance data is available. Among E. coli and ESKAPE pathogens, this review is mainly focused on E. coli, K. pneumoniae, P. aeruginosa and A. baumannii, as the resistance data against these pathogens is highly variable worldwide and is gathering massive attention owing to the challenges, severity of infections and treatment threats posed by these pathogens. Out of 22 countries studied in this report, none reported the presence of Enterococcus faecium expressing ESBL; hence, this review did not focus on other types of Enterococci reported from these countries during period of 2000 through 2020. The search words were "antibiotics resistance", "Arab countries" and "Gram-negative pathogens".

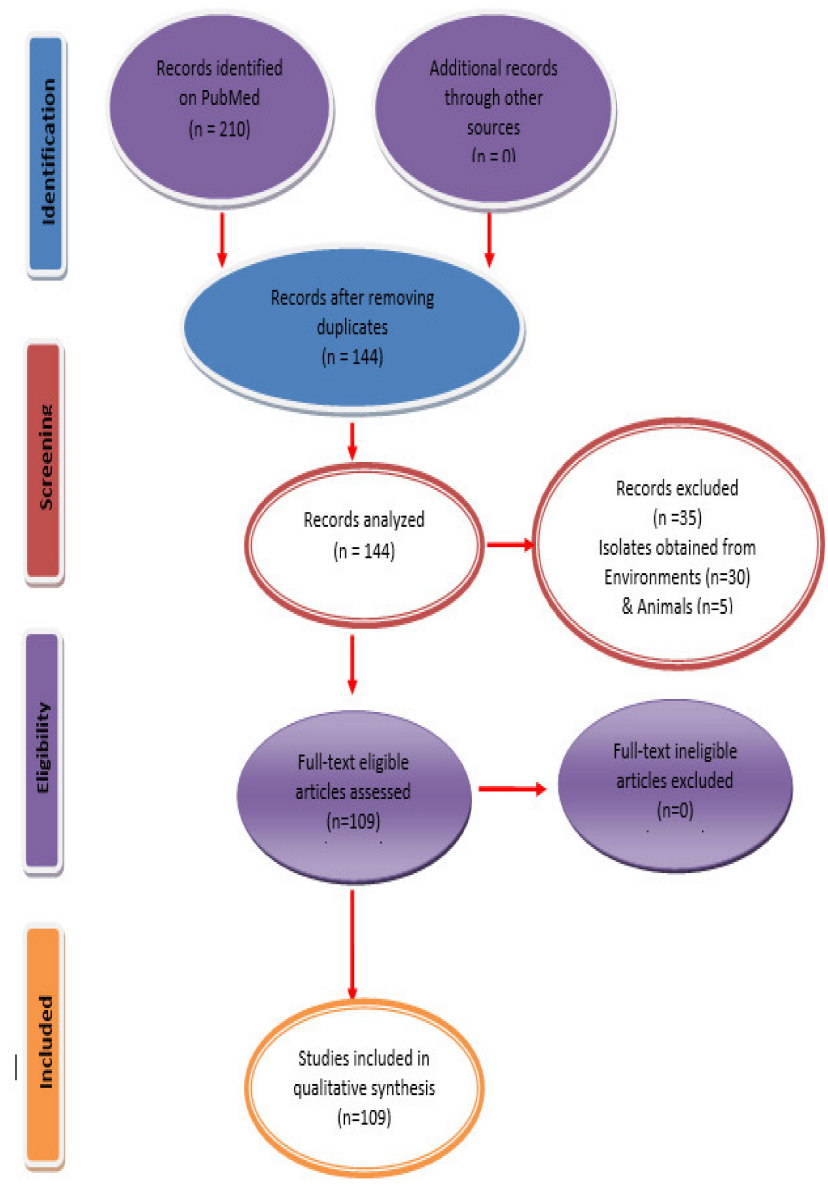

Figure 1. PRISMA flow diagram for study inclusion. PRISMA = preferred reporting items for systematic reviews and meta-analysis. 
Data selection: Inclusion criteria were studies published in English, the date of publication between 1 January 2000 and 29 February 2020, original research, human reports, reports on one or more of ESKAPE Pathogens with or without $E$. coli, and reports on resistance cases indicating $\beta$-lactamase.

Data extraction: Relevant data were extracted using a standardized form of collection from published articles. The analyses included: country, year of isolate collection, cultures isolated from various clinical specimens such as intra-abdominal, urinary tract, skin, wound and respiratory infections. The bacterial species analyzed were: E. coli, K. pneumoniae, A. baumannii, P. aeruginosa and Enterobacter spp. The number of isolates tested and the antibiotic susceptibility shown here is based on the Clinical Laboratory Standard Institute (CLSI, USA) interpretive criteria. Both phenotypic (disk diffusion methods) and genotypic (PCR technique) data were taken into consideration while estimating the \% prevalence of ESBLs.

Statistical analysis: Using SPSS version $26^{\circledR}$ of statistical software (IBM, USA), data were generated and analyzed. Descriptive statistics were determined using the marginal mean function in SPSS and the calculated mean was estimated.

\section{Results}

Due to globalization, the emergence and spread of antibiotic resistance among organisms causing frequent outbreaks has become prevalent. Nineteen out of twenty-two Arab countries (86.3\%) reported the occurrence of antimicrobial resistance either in E. coli or ESKAPE pathogens. Similar data were not found for Mauritania, Somalia, and the Comoros Islands. Between January 2000 and February 2020, there were 109 articles published on antibiotic resistance and $\beta$-lactamase(s) from 22 Arab countries.

\subsection{Saudi Arabia}

There were a total of thirty single or multiple hospital-based surveillance studies, which evaluated the prevalence of antimicrobial resistance among E. coli and ESKAPE pathogens. These studies comprised of $(n=52,033)$ E. coli and ESKAPE pathogens of which, E. coli were the highest $(n=22,493)$ followed by K. pneumoniae $(n=11,959)$, P. aeruginosa $(n=9854)$, S. aureus $(n=3829)$, A. baumannii $(n=2582)$, and Enterobacter spp. $(n=1316)$. Most of these isolates were recovered from patients admitted to Intensive Care Units (ICU) and patients with complicated Urinary Tract Infections (cUTI). Studies reported from Saudi Arabia showed significant increased resistance rates to various antimicrobial agents during the years 2000 through 2020. In comparison to $\beta$-lactam and beta-lactamase inhibitors (amoxicillin-clavulanic acid and piperacillin-tazobacam) resistance for standalone cephalosporins, such as cefuroxime, cefotaxime, ceftazidime, and cefepime was considerably high. Similarly, increased resistance rates were observed for aminoglycosides (gentamicin and amikacin), and quinolones (ciprofloxacin) compared to relatively lower resistance to carbapenem, imipenem and meropenem, shown in Table 1 [11-27].

Antibiotic resistance trends were also well supported by the identification of $\beta$-lactamases in these isolates. Isolates expressing various ESBLs were confirmed by double-disk potentiation method, thirteen studies from Saudi Arabia reported the phenotypic prevalence of ESBLs in E. coli and ESKAPE pathogens. These studies showed that during the initial study period of year 2000, ESBL prevalence was relatively low $(4.8 \%)$, but increased dramatically to $72 \%$ by 2020 in these countries based on the data obtained from 93,961 clinical samples $[13,14,19,20,22,24,25,28-33]$. The PCR analysis of various $\beta$-lactamases traits shown in Table 2 indicates that the prevalence of $b l a_{\mathrm{SHV}}, b l a_{\mathrm{TEM}}$ and $b l a_{\mathrm{CTX}-\mathrm{M}}$ among the E. coli and ESKAPE pathogens increased from between $2.6-8.5$ to $84.1-97.3 \%$, the $b l a_{\mathrm{OXA}}$, enzyme during this period increased from $26.2 \%$ to $85.7 \%$, and increasing resistance for $b l a_{\mathrm{PER}} b l a_{\mathrm{GES}}$ $\beta$-lactamases was also demonstrated. On the other hand, $b l a_{\mathrm{VIM}}$ and $b l a_{\mathrm{NDM}}$-lactamases were the most prevalent metallo- $\beta$-lactamases resistance encoding genes, showing a remarkable increase, along with the bla $_{\mathrm{IMP}}$ trait $[11,12,15-21,24,25,28,29,33-37]$. 
Table 1. Increased resistance rates to antimicrobial agents in E. coli and ESKAPE pathogens in the Arabian region for the years $2000-2020$.

\begin{tabular}{|c|c|c|c|c|c|c|c|c|c|c|c|c|}
\hline \multirow{2}{*}{ Country } & \multicolumn{12}{|c|}{ Increased Antimicrobial Resistance Rates during 2000-2020 } \\
\hline & CXM & GAZ & CPM & СTX & AUG & TPZ & CIP & $\mathrm{AK}$ & $\mathrm{CN}$ & MEM & IMP & ATM \\
\hline $\begin{array}{c}\text { Saudi } \\
\text { Arabia }\end{array}$ & $54 \%$ to $80 \%$ & $16.6 \%$ to $95 \%$ & $8.3 \%$ to $83 \%$ & $4.4 \%$ to $97 \%$ & $25 \%$ to $86 \%$ & $4.9 \%$ to $33.3 \%$ & $24 \%$ to $94.5 \%$ & $23.5 \%$ to $82 \%$ & $29 \%$ to $91.6 \%$ & $0 \%$ to $57.4 \%$ & $0 \%$ to $63.6 \%$ & $4.9 \%$ to $99 \%$ \\
\hline Qatar & - & $93.6 \%$ & $99 \%$ & - & $92 \%$ & $22 \%$ to $50 \%$ & $34.4 \%$ to $91.7 \%$ & $3 \%$ to $99 \%$ & $28 \%$ to $99 \%$ & $0 \%$ to $58.3 \%$ & - & - \\
\hline Kuwait & $100 \%$ & - & $32.8 \%$ & - & - & $32.8 \%$ to $97.8 \%$ & $31.1 \%$ to $100 \%$ & $23 \%$ to $93.5 \%$ & $45 \%$ & $54 \%$ & $32.8 \%$ to $100 \%$ & - \\
\hline Oman & - & - & - & $24 \%$ to $45 \%$ & $66 \%$ & $22 \%$ to $99 \%$ & $17.7 \%$ to $25 \%$ & $12.7 \%$ & $12.7 \%$ & - & - & - \\
\hline Iraq & & $36.3 \%$ to $87 \%$ & $50 \%$ to $78 \%$ & - & $37.5 \%$ to $50 \%$ & $86 \%$ to $87 \%$ & $40 \%$ to $86 \%$ & $57.1 \%$ to $75 \%$ & $38.3 \%$ to $95 \%$ & $37.5 \%$ to $56 \%$ & - & - \\
\hline Lebanon & - & $86.7 \%$ to $99 \%$ & $12 \%$ to $94.1 \%$ & $87.8 \%$ to $97.5 \%$ & - & $17 \%$ to $51.2 \%$ & $35 \%$ to $93.3 \%$ & $4 \%$ to $17.7 \%$ & $63.2 \%$ to $85.6 \%$ & $2.9 \%$ to $90 \%$ & $4.4 \%$ to $90 \%$ & $98.5 \%$ \\
\hline Palestine & $99 \%$, & $55 \%$ & - & $71 \%$ & $32 \%$ to $33.3 \%$ & - & $56 \%$ to $66.7 \%$ & $33.3 \%$ & $27 \%$ to $33.3 \%$ & - & $20 \%$ to $22 \%$ & - \\
\hline Egypt & $77 \%$ to $100 \%$ & $60.6 \%$ to $94.1 \%$ & $75 \%$ to $98.8 \%$ & $100 \%$ & $55 \%$ & $22.5 \%$ to $42.4 \%$ & $34.4 \%$ to $77.6 \%$ & $18.8 \%$ to $32.8 \%$ & $45 \%$ to $52.2 \%$ & $45.9 \%$ to $93.9 \%$ & $15 \%$ to $93.9 \%$ & $21.2 \%$ to $85.8 \%$ \\
\hline Tunisia & $100 \%$ & $72.2 \%$ & - & - & - & - & $48.5 \%$ to $62 \%$ & $95 \%$ & $92 \%$ to $93 \%$ & - & $0.8 \%$ & - \\
\hline
\end{tabular}

$\mathrm{CN}=$ Gentamycin, $\mathrm{CTX}=$ Cefotaxime, $\mathrm{AK}=$ Amikacin, $\mathrm{IPM}=$ Imipenem, MEM = Meropenem, GAZ = Ceftazidime, CPM = Cefepime, CIP = Ciprofloxacin, TPZ = Piperacillin-tazobactam, $\mathrm{ATM}=$ Aztreonam, $\mathrm{AUG}=$ amoxycillin-clavulanate, $\mathrm{CXM}=$ cefuroxim

Table 2. Increased prevalence for the $\beta$-lactamases genes in E. coli and ESKAPE pathogens in Arabian region for the years $2000-2020$.

\begin{tabular}{|c|c|c|c|c|c|c|c|c|c|c|}
\hline \multirow{2}{*}{ Country } & \multicolumn{10}{|c|}{ Increased $\beta$-lactamases Genes Rates during 2000-2020 } \\
\hline & $b l a_{\mathrm{SHV}}$ & $b l a_{\mathrm{TEM}}$ & $b l a_{\text {СТХ-M }}$ & $b l a_{\mathrm{OXA}}$ & bla $a_{\text {PER }}$ & $b l a_{\mathrm{GES}}$ & $b l a_{\mathrm{VIM}}$ & $b l a_{\mathrm{IMP}}$ & $b l a_{\text {NDM }}$ & $b l a_{\mathrm{VEB}}$ \\
\hline Saudi Arabia & $3.2 \%$ to $97.3 \%$ & $2.6 \%$ to $84.1 \%$ & $8.5 \%$ to $87 \%$ & $26.2 \%$ to $85.7 \%$ & $49.1 \%$ to $76.3 \%$ & $21.7 \%$ to $34.5 \%$ & $7 \%$ to $32 \%$ & $9 \%$ & $7.4 \%$ to $55 \%$ & \\
\hline Emirates & $4.4 \%$ & & $21.3 \%$ & $6.4 \% \& 53.3 \%$ & & & & & $24.7 \%$. & \\
\hline Qatar & $53.2 \%$ & $40.4 \%$ & $59 \%$ to $66.1 \%$ & $100 \%$ & & & & & & \\
\hline Iraq & $24 \%$ & $20 \%$ to $46 \%$ & $26 \%$ & $58 \%$ & $17 \%$ & & $5 \%$ & $9.1 \%$ to $50 \%$ & $67.2 \%$ & $30 \%$ \\
\hline Lebanon & $88.2 \%$ & $63.2 \%$ & $41.2 \%$ to $86.7 \%$ & $5.8 \%$ to $96.7 \%$ & & $75 \%$ & $50 \%$ & $17 \%$ & 14.7 to $30 \%$ & \\
\hline
\end{tabular}




\subsection{United Arab Emirates}

There were five single or multiple hospital-based surveillance studies demonstrating the prevalence of antimicrobial resistance among E. coli and ESKAPE pathogens including 1191 isolates, of which E. coli was the highest $(n=654)$, followed by K. pneumoniae $(n=524)$, and Enterobacter spp. $(n=13)$. These pathogens were mostly isolated from patients admitted to the ICU and also from patients with cUTI and blood samples (septicemia). These studies demonstrated substantially higher rates of resistance to various antimicrobials in the last 20 years, for example, between 2014 and 2016, the resistance to ceftazidime, cefotaxime and ciprofloxacin was 72\%, 73\% and 74\%, respectively, [38]. Additionally, between 2011 and 2012, the resistance to meropenem and imipenem was 7\% and 9\%, respectively, [39]. The increase in antibiotic resistance in these isolates was also well illustrated by the detection of $\beta$-lactamases. Isolates expressing different ESBLs were verified using a double-disk potentiation method, and three studies from the United Arab Emirates documented the phenotypic prevalence of ESBLs in E. coli and ESKAPE pathogens. These studies showed that during the study period (2000-2020), ESBL rates increased significantly from 36.2 to $75 \%$ [38,40,41].

The PCR analysis of various $\beta$-lactamase-encoding genes was carried out; the results shown in Table 2 indicate that bla $\mathrm{CTX}-\mathrm{M}$ was the most common ESBL enzyme among E. coli and ESKAPE pathogens, which was $21.3 \%$ in 2008 [41]. Other relatively less prevalent $\beta$-lactamase-genes were $b l a_{\text {OXA }}$, which was $6.4 \%$ in $2011 / 2012$ and increased to $53.3 \%$ in 2015/2016 [39,42], presence of bla $a_{\mathrm{SHV}}$ was also demonstrated during the study period. These studies showed that $b l a_{\mathrm{NDM}}$ was the prevalent metallo- $\beta$-lactamase in the UAE.

\subsection{Qatar}

Seven single or multiple hospital-based surveillance studies were performed to assess the prevalence of antimicrobial resistance among E. coli and ESKAPE pathogens from Qatar, including 770 isolates of which E. coli isolates were the highest $(n=448)$ followed by K. pneumoniae $(n=168)$, $P$. aeruginosa $(n=106)$, A. baumannii $(n=48)$. Most of these isolates were recovered from patients admitted to the ICU and patients with cUTI or cystic fibrosis. During 2000-2020, antibiotic resistance was significantly increased in Qatar; the data presented in Table 1 show that resistance to 3rd- and 4th-generation cephalosporins; ceftazidime, and cefepime along with commonly used $\beta$-lactam/beta-lactamase inhibitor combinations, amoxicillin-clavulanic acid and piperacillin-tazobactam. Higher resistance was also seen for aminoglycosides; gentamycin and amikacin (aminoglycosides), ciprofloxacin (quinolone), while relatively lower resistance was recorded for meropenem (carbapenem) [43-45]. The increase in antibiotic resistance in these isolates was well substantiated by the identification of $\beta$-lactamases. The isolates expressing different ESBLs were verified using a double-disk potentiation method, while studies from Qatar documented the phenotypic prevalence of ESBLs in E. coli and ESKAPE pathogens. Those studies showed that during the study period, ESBL prevalence ranged between $9 \%$ to $31.7 \%$ based on the data with clinical isolates $(n=2166)[44,46,47]$. Molecular characterization with the use of PCR demonstrated that $b l a_{\mathrm{OXA}}$ and bla $a_{\text {CTX-M }}$ were the most prevalent ESBL traits among E. coli and ESKAPE pathogens, a smaller number of clinical isolates were reported to express $b l a_{\mathrm{TEM}}$ and, $b l a_{\mathrm{SHV}}$ ESBL traits (Table 2) [44,46-48].

\subsection{Kuwait}

Nine single or multiple hospital surveillance studies were performed to evaluate the prevalence of antimicrobial resistance among E. coli and ESKAPE pathogens, which included 2233 isolates of which E. coli isolates were the highest $(n=1206)$ followed by K. pneumoniae $(n=669)$, P. aeruginosa $(n=79), A$. baumannii $(n=63)$, and Enterobacter spp. $(n=7)$. Most of these isolates were recovered from patients admitted to the ICU and blood samples. In Kuwait, during the period 2000 through 2020, increasing resistance to 3rd-generation cephalosporins (cefuroxime, and cefepime), and $\beta$-lactam/ $\beta$-lactamase inhibitor (piperacillin-tazobactam), carbapenem (imipenem and meropenem) 
along with aminoglycosides (gentamicin and amikacin) and quinolones (ciprofloxacin) were becoming prevalent (see Table 1) [49-51]. These increasing trends of antibiotic resistance were also studied by the detection of $\beta$-lactamases in these isolates. Studies from Kuwait documented the phenotypic prevalence of ESBLs in E. coli and ESKAPE pathogens by the double potentiation method. These studies showed that the phenotypic prevalence of ESBL was between $31.7 \%$ and $32.8 \%$ in E. coli and ESKAPE pathogens [50,52]. In addition, the PCR amplification of various $\beta$-lactamases-resistance genes revealed that the most prevalent ESBLs distributed among E. coli and ESKAPE pathogens expressed the bla $_{\mathrm{CTX}-\mathrm{M}}$

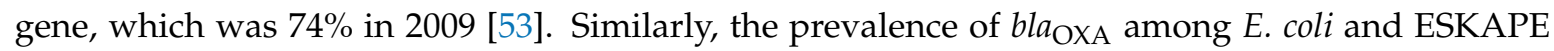
pathogens varied from 11.4 to $100 \%$ [50,54], for bla $a_{\mathrm{VEB}} 2 \%$ [55] and for $b l a_{\mathrm{NDM}} 34.4 \%$ [50].

\subsection{Oman}

Four single or multiple hospital-based surveillance studies were performed to assess the prevalence of antimicrobial resistance among E. coli and ESKAPE pathogens. These studies comprised 607 isolates, of which E. coli isolates were the highest $(n=165)$ followed by K. pneumoniae $(n=112)$, P. aeruginosa $(n=48)$, S. aureus $(n=155)$, A. baumannii $(n=107)$, and Enterobacter spp. $(n=20)$. Most of these isolates were recovered from patients admitted to the ICU. These studies reported a significant increase in resistance rates to various antimicrobial agents over the last 20 years. The results shown in Table 1 indicate that in Oman, higher resistance to piperacillin-tazobactam was common during 2000-2020, while relatively lower resistance was reported against cefuroxime, amoxycillin-clavulanate, and aminoglycosides, such as gentamicin and amikacin, and quinolones (ciprofloxacin) [56-58].

The increase in antibiotic resistance in these isolates was also explained by the detection of $\beta$-lactamase enzymatic activity and encoding genes. Isolates expressing various ESBL activity were verified among E. coli and ESKAPE pathogens using a double-disk potentiation method. Such research showed that during the study period (2000-2020), the phenotypic prevalence of ESBL was between $5 \%$ and $14.9 \%$ in E. coli and ESKAPE pathogens [57,58]. Additionally, molecular studies showed that between 2010 and 2011, the prevalence of bla $a_{\mathrm{OXA}}$ and bla $a_{\mathrm{NDM}} \beta$-lactamase genes among E. coli and ESKAPE pathogens was $24.5 \%$ and $50 \%$, respectively, [59].

\subsection{Bahrain}

Three single or multiple hospital-based surveillance studies were performed to assess the prevalence of antimicrobial resistance among $E$. coli and ESKAPE pathogens. These studies comprised 2420 isolates, of which E. coli isolates were the highest $(n=1594)$ followed by K. pneumoniae $(n=704)$, P. aeruginosa $(n=60)$, and Enterobacter spp. $(n=62)$. The majority of these isolates were recovered from patients admitted to the ICU. In the last 20 years, a substantial increase in the resistance level of different antimicrobial agents has been recorded. In 2019 , resistance to ciprofloxacin was $100 \%$, ceftazidime $86 \%$, amikacin $72 \%$, gentamicin $86 \%$, meropenem $90 \%$, imipenem $80 \%$ and piperacillin-tazobactam $90 \%$ [60]. The increase in antibiotic resistance in these isolates was also well demonstrated by the detection of $\beta$-lactamases enzymatic activities or genes.

As in other studies, isolates expressing ESBL activity were verified by the double-disk potentiation method. Studies from Bahrain revealed the phenotypic prevalence of ESBLs in E. coli and ESKAPE pathogens. Such research showed that the phenotypic prevalence of ESBLs during the study period (2000-2020) was $22.6 \%$ [61]. Furthermore, the PCR mediated amplification of various $\beta$-lactamases genes was also undertaken. In 2011, a study conducted showed that $b l a_{\mathrm{SHV}}, b l a_{\mathrm{TEM}}$ and $b l a_{\mathrm{CTX}-\mathrm{M}}$ $\beta$-lactamases encoding genes were the most predominant markers among E. coli and ESKAPE pathogens and accounted for $37 \%, 36.1 \%$ and $36.1 \%$, respectively [62]. Another study conducted in Bahrain in 2011 showed that $b l a_{\mathrm{VIM}}$ and $b l a_{\mathrm{NDM}}$ were present in $47.5 \%$ and $2.5 \%$ of $E$. coli and ESKAPE pathogens [60] and $b l a_{\mathrm{VIM}}$ was the most common metallo- $\beta$-lactamase encoding gene identified. 


\subsection{Yemen}

Three single or multiple hospital-based surveillance studies were performed to determine the prevalence of antimicrobial resistance among E. coli and ESKAPE pathogens. These studies included 143 isolates, of which E. coli were the highest $(n=130)$ followed by K. pneumoniae $(n=8)$, A. baumannii $(n=3)$ and Enterobacter spp. $(n=2)$. These studies demonstrated slightly higher levels of resistance to various antimicrobials. For example, between 2014 and 2018, the resistance to cefuroxime was $95 \%$, amoxycillin-clavulanate $90.9 \%$, ciprofloxacin $90.9 \%$, meropenem $95 \%$ and imipenem 95\% $[63,64]$. The increase in antibiotic resistance in these isolates was also justified by the detection of $\beta$-lactamases. Isolates expressing various ESBL phenotypes were observed using a double-disk potentiation method. Studies from Yemen revealed the phenotypic prevalence of ESBLs in E. coli and ESKAPE pathogens. These studies showed that during the study period the phenotypic prevalence of ESBL increased from 33\% to 100\% [63,64]. Furthermore, analysis based on PCR studies was also undertaken. Bacteria expressing $b l a_{\mathrm{SHV}}, b l a_{\mathrm{TEM}}$ and $b l a_{\mathrm{CTX}-\mathrm{M}}$ were the most predominant ESBLs among E. coli and ESKAPE pathogens. In 2014, bla $a_{\mathrm{SHV}}$ was found in $80 \%$ of the population, $b l a_{\mathrm{TEM}}$ in $70 \%, b l a_{\mathrm{CTX}-\mathrm{M}}$ in $80 \%$ [63] and bla ${ }_{\mathrm{OXA}}$ in 10\% [65]. This study showed that the prevalence of $b l a_{\mathrm{NDM}}$ was $100 \%$ in 2014 [63].

\subsection{Jordan}

There were four single or multiple hospital-based surveillance studies, which evaluated the prevalence of antimicrobial resistance among E. coli and ESKAPE pathogens. Most of these isolates were recovered from ICU patients with cUTI and respiratory tract infections (RTI). Changing trends of antibiotic resistance in Jordan were also substantiated by data providing the phenotypic presence of $\beta$-lactamases. Isolates showing phenotypic expression of various ESBLs were verified using a double-disk potentiation method. These studies showed that in the study period, ESBL prevalence was relatively low (22.6\% in 2009), but increased dramatically to $62 \%$ in 2019 , as reported by a Jordan-based study on data obtained from 950 clinical samples [66,67]. Molecular biology studies demonstrated that $b l a_{\mathrm{CTX}-\mathrm{M}}$ was the most prevalent ESBL gene among E. coli and ESKAPE pathogens. It was detected in $25 \%$ of the population in 2000 and reached $68.9 \%$ in 2020 [67-69] while blaSHV increased from $12.5 \%$ to $20 \%$. bla $a_{\mathrm{TEM}}$ and $b l a_{\mathrm{VEB}}$ both accounted for $18.9 \%$ of the population [67-69], and between 2012 and 2013, bla $a_{\mathrm{OXA}}$ and bla $a_{\mathrm{NDM}}$ were found in 71.5\% and $28.5 \%$ of E. coli and ESKAPE bacteria, respectively, [69].

\subsection{Iraq}

Five single or multiple hospital-based surveillance studies were performed to assess the prevalence of antimicrobial resistance among E. coli and ESKAPE pathogens, which included 382 isolates of which $E$. coli isolates $(n=49)$, K. pneumoniae $(n=98)$, P. aeruginosa $(n=196)$, S. aureus $(n=17)$, A. baumannii $(n=9)$, and Enterobacter spp. $(n=13)$. The majority of these isolates were recovered from ICU hospitalized patients and patients with cUTIs. The results shown in Table 1 indicate that in Iraq during 2000 through 2020, resistance to 3rd- and 4th-generation standalone cephalosprins; ceftazidime, and cefepime was higher than that of $\beta$-lactam/ $\beta$-lactamase inhibitor combination, amoxicillin-clavulanic acid. Curiously, resistance to piperacillin-tazobactam combination, aminoglycosides (gentamicin and amikacin) was higher than carbapenems such as; imipenem and meropenem [70-73]. These increases in antibiotic resistance in these isolates were correlated with the identification of $\beta$-lactamases phenotypically. Isolates expressing various ESBLs were verified by using a double-disk potentiation method. Studies based on the 402 clinical samples have revealed that the incidence of ESBLs pathogens was comparatively low (13.5\%) in 2000, but significantly increased to $61.5 \%$ over time $[70,72,73]$. The results shown in Table 2 represent molecular characterization of the ESBL trait with PCR analysis. Table 2 shows that $b l a_{\mathrm{SHV}}, b l a_{\mathrm{TEM}}$ and $b l a_{\mathrm{CTX}-\mathrm{M}}$ were the most predominant ESBLs among E. coli and ESKAPE pathogens, and an increasing trend was also observed for bla $a_{\mathrm{OXA}}, b l a_{\mathrm{PER}}$, and bla $a_{\mathrm{VEB}}$ 
ESBL traits. bla $a_{\mathrm{NDM}}$ was the most prevalent metallo- $\beta$-lactamase encoding gene, with fewer isolates demonstrating expression of the $b l a_{\mathrm{VIM}}$ and $b l a_{\mathrm{IMP}}$ ESBL trait [71-74].

\subsection{Syria}

Extremely limited antibiotic surveillance data are available for Syria. They are limited to two single or multiple hospital-based surveillance studies comprising of 364 isolates of which 104 were E. coli and 260 A. baumannii. The majority of these isolates were recovered from ICU hospitalized patients and patients with UTIs. One study showed a significant increase in resistance to various antimicrobial agents over the last 20 years. Between 2008 and 2011 resistance to cefotaxime reached $91.4 \%$, ceftazidime $80.6 \%$, cefepime $84.7 \%$, amoxycillin-clavulanate $93.2 \%$, ciprofloxacin $81.2 \%$, amikacin $78.3 \%$, gentamicin $82.7 \%$, piperacillin-tazobactam 91.2\%, and aztreonam 98.5\% [75]. Moreover, isolates expressing various ESBLs were verified using a double-disk potentiation method. Studies from Syria documented the phenotypic prevalence of ESBLs among E. coli and ESKAPE pathogens. These studies showed that the phenotypic prevalence of ESBL was 52\% [76].

\subsection{Lebanon}

Five single or multiple hospital monitoring studies were conducted to assess the prevalence of antimicrobial resistance among $E$. coli and ESKAPE pathogens including 2837 isolates of which E. coli isolates were highest $(n=2000)$ followed by K. pneumoniae $(n=676)$, P. aeruginosa $(n=40)$ and A. baumannii $(n=121)$. Most of these isolates were recovered from ICU hospitalized patients and patients suffering from cUTIs. The results shown in Table 1 indicate that in Lebanon, during 2020 through 2020, resistance to 3rd- and 4th-generation cephalosporins, such as cefotaxime, ceftazidime, and cefepime, aminoglycosides, e.g., gentamicin and amikacin, ciprofloxacin-a quinolone drug-and carbapenems, such as imipenem and meropenem, was higher. Curiously, resistance to piperacillin-tazobactam was relatively lower [77-80]. The increasing antibiotic resistance trends in Lebanon were justified by characterization of $\beta$-lactamase phenotypic and genotypic activities. Isolates expressing various ESBLs were tested using a dual-disk potentiation method. ESBL prevalence was relatively low (24\%) in 2000 but increased dramatically to $84 \%$ in 2020 [78,81]. Molecular analysis carried with PCR, shown in Table 2 indicated that $b l a_{\mathrm{SHV}}, b l a_{\mathrm{TEM}}$ and $b l a_{\mathrm{CTX}-\mathrm{M}}$ were the most predominant ESBL-encoding genes among E. coli and ESKAPE pathogens, this increasing trend was also observed for $b l a_{\mathrm{OXA}}$, and $b l a_{\mathrm{GES}}$ ESBL traits. On the other hand, bla $a_{\text {VIM }}$ was the most common metallo- $\beta$-lactamass resistance encoding gene which showed remarkable increase, with fewer isolates shown to express the $b l a_{\mathrm{NDM}} \mathrm{ESBL}$ trait [77-81].

\subsection{Palestine}

Limited antibiotic susceptibility data are available from only two single hospital-based surveillance studies. Antimicrobial resistance among E. coli and ESKAPE pathogens comprised 119 isolates, out of which 101 were E. coli followed by K. pneumoniae $(n=15)$, and Enterobacter spp. $(n=3)$. The majority of these isolates were recovered from ICU hospitalized patients. These studies reported significantly increased resistance rates to various antimicrobial agents during the years 2000-2020. The results shown in Table 1 indicate that in Palestine during 2000 to 2020, resistance to 3rd-generation cephalosporins, i.e., cefuroxime, cefotaxime, ceftazidime, was higher. Interestingly, lower resistance was reported against amoxicillin-clavulanic acid, aminoglycosides (gentamicin and amikacin), quinolones (ciprofloxacin), and imipenem [82,83]. Isolates expressing various ESBLs, characterized by double-disk potentiation method, showed relatively low ESBL rates 20 years ago (35.3\%), which increased dramatically to $85.3 \%$ [82,83]. The molecular studies shown in Table 2 indicate that $b l a_{\mathrm{CTX}-\mathrm{M}}$ was the most predominant ESBL trait among E. coli and ESKAPE pathogens, which evolved from $71.4 \%$ to $100 \%$. A similar upward trend was also observed for bla $a_{\mathrm{TEM}}, b l a_{\mathrm{OXA}}$ and $b l a_{\mathrm{SHV}}$ ESBL traits $[82,83]$. 


\subsection{Egypt}

Six single or multiple hospital-based surveillance studies were carried out to evaluate the prevalence of antimicrobial resistance among $E$. coli and ESKAPE pathogens. These studies comprised 1289 isolates, of which E. coli were the highest $(n=661)$, followed by K. pneumoniae $(n=246)$, P. aeruginosa $(n=356)$, A. baumannii $(n=7)$, and Enterobacter spp. $(n=19)$. Most of these isolates were recovered from ICU inpatients and patients with complex urinary tract infections. The results shown in Table 1 indicate that in Egypt from 2000 through 2020, resistance to various cephalosporins, such as cefuroxime, cefotaxime, ceftazidime, and cefepime, was higher than that to b-lactam/b-lactamase inhibitor combinations, e.g., amoxicillin-clavulanic acid and piperacillin-tazobactam. A rise in resistance was reported against aminoglycosides; gentamcin/amikacin, ciprofloxacin (a quinolone drug) and carbapenems, i.e., imipenem and meropenem [84-89]. The increase in antibiotic resistance in these isolates has also been demonstrated by $\beta$-lactamase detection. These studies from Egypt reported the phenotypic prevalence of ESBLs in E. coli and ESKAPE pathogens with ESBL rate of 7.4\%, which increased to $48.9 \%$ [84,89-92]. Molecular characterization of the ESBL trait with PCR showed that $b l a_{\mathrm{SHV}}, b l a_{\mathrm{TEM}}$ and $b l a_{\mathrm{CTX}-\mathrm{M}}$ were the most predominant traits among E. coli and ESKAPE pathogens. An increasing trend of bla OXA ESBL was also documented during 2000-2020, as shown in Table 2. An increasing trend was also observed for bla $a_{\mathrm{PER}}$ and $b l_{\mathrm{GES}}$ ESBL traits. On the other hand, $b l a_{\mathrm{VIM}}$ and $b l a_{\mathrm{IMP}}$ were the most prevalent metallo- $\beta$-lactamases resistance encoding genes which showed a remarkable increase, along with $b l a_{\mathrm{NDM}}[84,88,90-93]$.

\subsection{Libya}

Based on susceptibility studies undertaken by two single or multiple tertiary care hospitals from Libya, the prevalence of antimicrobial resistance among E. coli and ESKAPE pathogens was determined. These studies involved 433 isolates, of which $E$. coli were the highest $(n=397)$ followed by K. pneumoniae $(n=36)$. Most of these isolates were recovered from ICU inpatients. These studies reported significantly increased resistance rates to $\beta$-lactams. For instance, resistance to cefotaxime was $93 \%$, ceftazidime $93 \%$ and cefepime was $93 \%$ [87]. Isolates expressing various ESBLs were confirmed using a dual-disk potentiation method, wherein ESBL prevalence was found to be $66.6-67.6 \%[87,94]$. Furthermore, analysis based on molecular studies involving PCR mediated amplification of various $\beta$-lactamases showed that bla $_{\mathrm{CTX}-\mathrm{M}}(51.7$ to $85.9 \%)$ were the most predominant ESBLs in E. coli and ESKAPE pathogens [87,94], with bla $a_{\mathrm{SHV}}$ at $21.8 \%, b l a_{\mathrm{TEM}} 35 \%$ and $b l a_{\mathrm{OXA}} 11.4 \%$ in 2016 [94].

\subsection{Algeria}

With four single or multiple hospital-based surveillance studies, the prevalence of antimicrobial resistance among E. coli and ESKAPE pathogens was assessed. Overall, 668 isolates were found in these studies, of which E. coli $(n=232)$ and K. pneumoniae $(n=246)$ were the highest, along with S. aureus $(n=106)$, A. baumannii $(n=17)$, and Enterobacter spp. $(n=67)$. Most of these isolates were recovered from ICU inpatients and patients with complex urinary tract infections. These studies reported significantly increased resistance rates to various $\beta$-lactam antibiotics. For instance, in 2008 cefuroxime resistance was $87.3 \%$, cefotaxime $59 \%$, aztreonam $33.3 \%$, and ceftazidime $12.8 \%$ [95]. Isolates expressing various ESBLs were tested using a dual-disk potentiation method, which showed increased ESBL rates from $17.7 \%$ to $47.6 \%$ during the study period [95-97]. Additionally, based on the molecular analysis, it was observed that in $2009, b_{\text {SHV }}$ was $10 \%$ [96], bla $a_{\mathrm{TEM}} 19.9 \%$ to $70 \%[95,96,98]$, bla $_{\mathrm{CTX}-\mathrm{M}} 19.9 \%$ to $100 \%$ [95-98], and in 2013 bla $_{\mathrm{VIM}}$ was $82.3 \%$ [99].

\subsection{Tunisia}

A total of 1650 E. coli and ESKAPE pathogens, E. coli $(n=368)$, K. pneumoniae $(n=811)$, P. aeruginosa $(n=210)$, A. baumannii $(n=246)$, and Enterobacter spp. $(n=15)$, were recovered from six single or multiple hospital-based surveillance studies to assess the prevalence of antimicrobial 
resistance in these pathogens. Most of these isolates were recovered from ICU inpatients. The results shown in Table 1 indicate that in Tunisia during 2000 to 2020 resistance to 3rd-generation cephalosporins, such as cefuroxime and ceftazidime, aminoglycosides, e.g., gentamicin and amikacin, was higher than resistance to ciprofloxacin, a quinolone drug. Curiously, most reports showed susceptibility to the carbapenem drug imipenem [100-103]. Based on phenotypic methods, the prevalence of ESBLs in E. coli and ESKAPE pathogens was determined, which was $7.3 \%$ in year 2000 and reached $100 \%$ [101-104]. Molecular data showed that $b l a_{\mathrm{SHV}}, b l a_{\mathrm{CTX}-\mathrm{M}}$ and $b l a_{\mathrm{TEM}}$ were the most predominant ESBLs in E. coli and ESKAPE pathogens, which were $57.3 \%$ and increased to $92.1 \%$ [100-102], from $6.6 \%$ to $83.3 \%$ [100-103] and 0.6 to $51.6 \%$ [100-103], respectively. A similar increase in $\beta$-lactamase was observed for $b l a_{\mathrm{OXA}}-50 \%$ to $93.9 \%$ [100,101,105], and between 2013 and 2015, bla $a_{\mathrm{NDM}}$ was 4.4\% [105].

\subsection{Morocco}

Antibiotic resistance data were available for 904 clinical isolates, of which E. coli was the highest ( $n=639$ ) along with some K. pneumoniae $(n=113)$, P. aeruginosa $(n=123)$, and Enterobacter spp. $(n=15)$. These data were based on four single or multiple hospital-based surveillance studies and the majority of isolates were from ICU patients. Between 2012 and 2014, studies showed resistance to ceftazidime $8.8 \%$, ciprofloxacin $39.5 \%$, amikacin $11.8 \%$, gentamicin $48.5 \%$, imipenem $36.8 \%$, meropenem $27.9 \%$, piperacillin-tazobactam 9.8\%, and aztreonam 35.3\% [106]. The increase in antibiotic resistance in these isolates was also well demonstrated by $\beta$-lactamase detection. Isolates expressing various ESBLs were tested using a dual-disk potentiation method. Moroccan studies reported the phenotypic prevalence of ESBLs in E. coli and ESKAPE pathogens. These studies showed that, in the study period, ESBL prevalence was $1.3 \%$, which increased to $58 \%$ [107-109]. In addition, molecular studies showed that $b a_{\mathrm{SHV}}, \mathrm{bla}_{\mathrm{CTX}-\mathrm{M}}$, bla $a_{\mathrm{TEM}}$ were the most predominant ESBLs in E. coli and ESKAPE pathogens, which showed a dramatic rise during the study period such as $9.1 \%$ in 2000 increasing to $67.3 \%$ in 2020 [108,109], bla $a_{\mathrm{TEM}} 42.8 \%$ [108], bla $_{\mathrm{CTX}-\mathrm{M}} 1.1$ to $90.9 \%$ [107-109], bla OXA $_{13 \%}$ [109], and bla $a_{\mathrm{VIM}} 6 \%$ [106].

\subsection{Sudan}

To assess the prevalence of antimicrobial resistance among E. coli and ESKAPE pathogens, three single or multiple hospital-based surveillance studies were conducted. These studies contain 823 isolates, of which E. coli $(n=450)$, K. pneumoniae $(n=315)$, S. aureus $(n=54)$, and A. baumannii $(n=4)$. Most of these isolates were obtained from ICU patients. These studies reported increased resistance rates to various antimicrobial agents. For instance, resistance to ceftazidime 55.6\% [110], ciprofloxacin $81.4 \%$ [111], amikacin $95.7 \%$ [111], cefotaxime $61.1 \%$ to $89 \%$ [110,111]. The increase in antibiotic resistance in these isolates has also been well demonstrated by $\beta$-lactamase detection. Isolates expressing various ESBLs were tested using a dual-disk potentiation method. Studies from Sudan reported the phenotypic prevalence of ESBLs among E. coli and ESKAPE pathogens. These studies showed that in the study period, ESBL prevalence ranged from $30.2 \%$ to $44.4 \%$ [110,111]. In addition, research was also conducted based on molecular experiments involving PCR mediated amplification of various $\beta$-lactamases. These studies showed that $b l a_{\mathrm{VIM}}$ was the most predominant MBLs in E. coli and ESKAPE pathogens, which were $b l a_{\mathrm{VIM}} 38.9 \%$, bla $a_{\mathrm{IMP}} 36.4 \%$, and $b a_{\mathrm{NDM}} 4.2 \%$ during 2015 to 2016 [112].

\subsection{Djibouti}

One single hospital-based surveillance study was conducted to assess the prevalence of antimicrobial resistance among E. coli. Limited data is available, with only 31 E. coli isolates. Based on the molecular data in 2019 involving PCR mediated amplification showed $b l a_{\text {TEM }} 10 \%$ and $b l a_{\text {CTX-M }} 96.8 \%$ [113].

\section{Discussion}

As shown in Table 3 and Figure 2, 19 of 22 Arab countries (86.3\%) provided antimicrobial resistance data on E. coli and ESKAPE pathogens, especially Gram-negatives. Similar data was not found for three countries: Mauritania, Somalia, and the Comoros Islands. Between January 2000 and February 2020, 
there were 109 articles published reviewing antibiotic resistance in Arab region countries. Among the E. coli and ESKAPE pathogens, the predominantly encountered pathogen was E. coli $(n=32,038)$, followed by K. pneumoniae ( $n=17,128)$, P. aeruginosa $(n=11,074)$, methicillin-resistant $S$. aureus (MRSA, $n=4370)$, A. baumannii $(n=3485)$ and Enterobacter spp. $(n=1574)$. Overall, the most prevalent Gram-negative pathogens in Arab regions were E. coli and Klebsiella spp., mainly encountered in respiratory infections, urinary tract infections and blood stream infections. P. aeruginosa and A. baumannii were mainly from respiratory infections associated with hospital acquired bacterial pneumonia and ventilator associated bacterial pneumonia in ICU settings. Meanwhile, infections caused by Enterobacter spp. were mainly reported from complicated digestive tract and urinary tract infection. To understand the antibiotic resistance trends in Gram-negative isolates, data containing a higher proportion of isolates from Saudi Arabia, Kuwait, Oman, Bahrain, Qatar, UAE, Egypt Sudan and Tunisia could be more helpful.

Table 3. Distribution of total E. coli and ESKAPE pathogens in separate Arab region countries during 2000-2020.

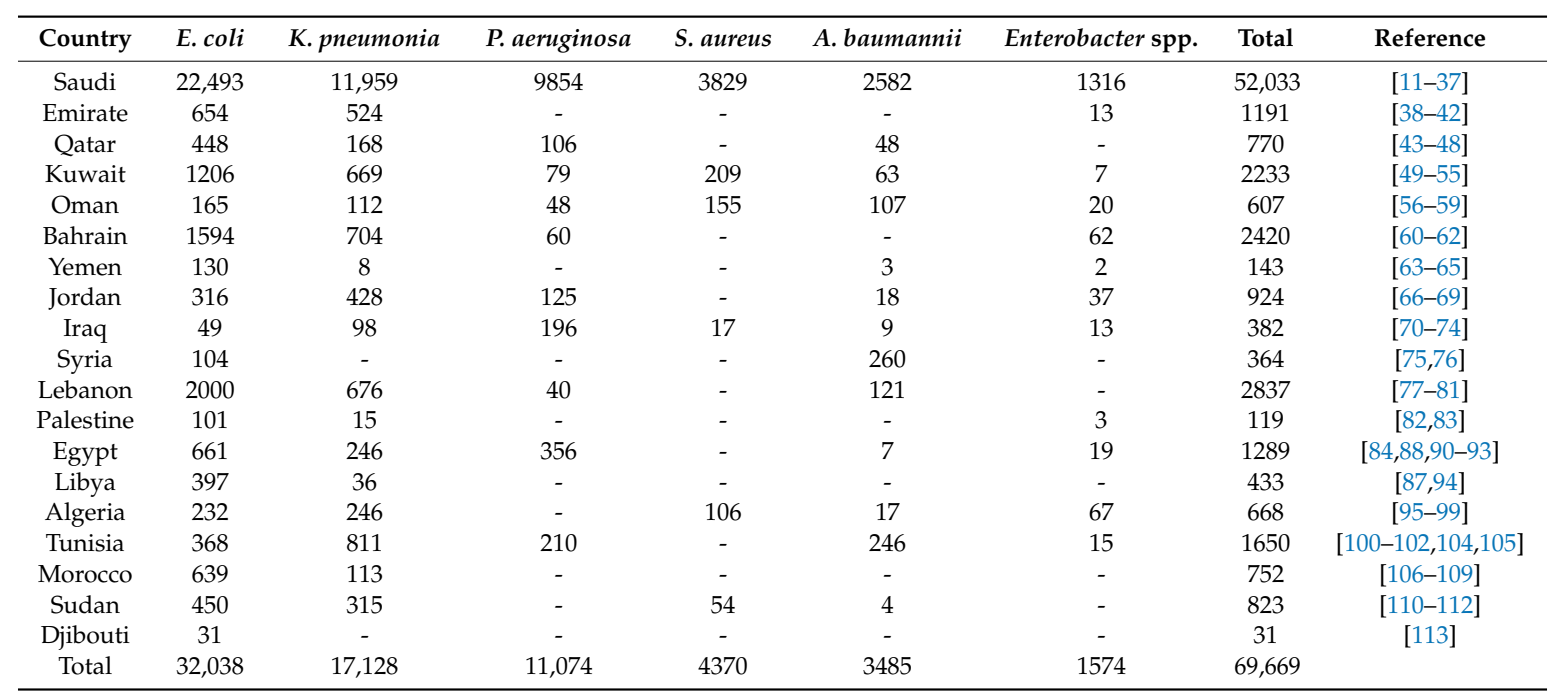

The data from these countries showed the distribution of E. coli and ESKAPE pathogens as shown in Figure 3. E. coli was highest, at $46 \%$, followed by K. pneumoniae, $25.3 \%$, and then P. aeruginosa, $16.2 \%$, S. aureus, $6.2 \%$, A. baumannii, $5 \%$, and Enterobacter spp., $2.3 \%$.

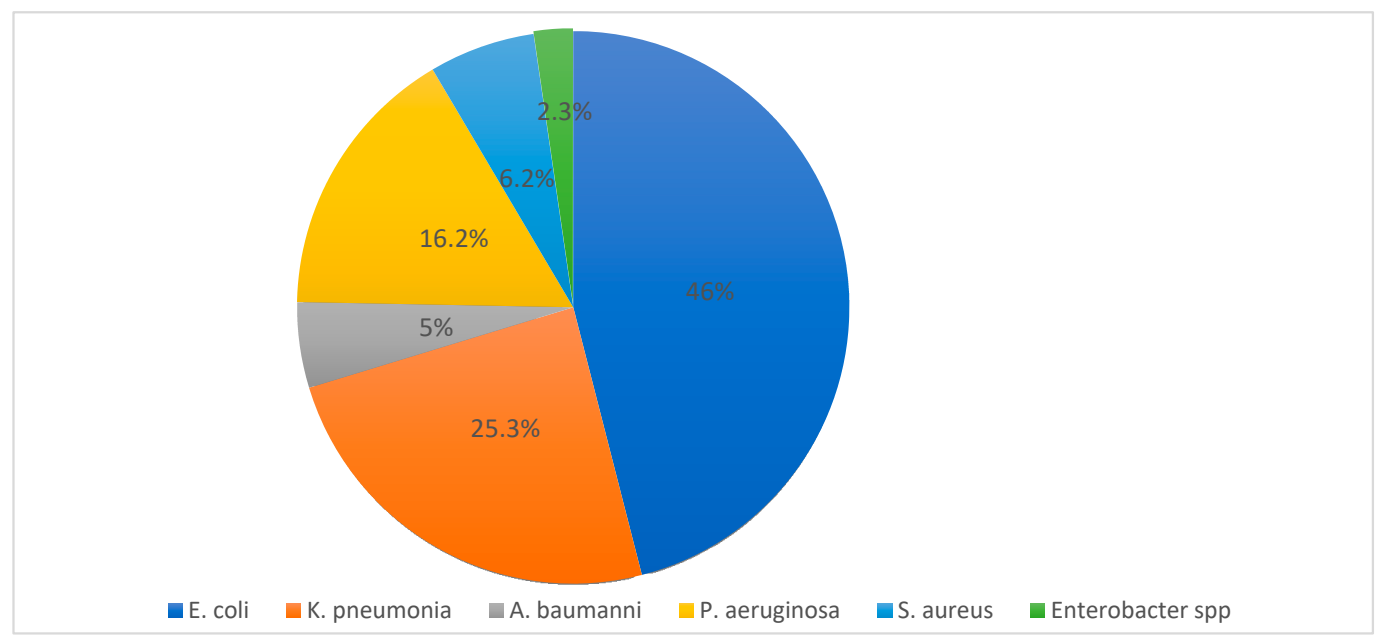

Figure 2. Percentage of distribution of E. coli and ESKAPE pathogens in the Arab region during 2000-2020. 
Additionally, the data from these countries showed significant increased resistance to cephalosporins such as cefuroxime, cefotaxime, ceftazidime, cefepime and a $\beta$-lactam and $\beta$-lactamase inhibitor combinations such as amoxicillin-clavulanic acid and piperacillin-tazobactam in the last 20 years. The mean values of resistance rates to cephalosporins (cefuroxime, cefotaxime, ceftazidime, and cefepime), and $\beta$-lactam and $\beta$-lactamase inhibitor combinations (amoxicillin-clavulanic acid and piperacillin-tazobactam) among E. coli and ESKAPE pathogens were (77.1\%, 71.8\%, 59.5\%, and $56.5 \%$ ), and (61.7\% and $45.3 \%)$, respectively. Similarly, higher resistance rates were observed for aminoglycosides (gentamicin and amikacin), quinolones (ciprofloxacin), and carbapenems (imipenem and meropenem) among E. coli and ESKAPE pathogens was (45.7\% and 48.9\%), (56.2\%), and (37.5\% and 45.2\%), respectively. As shown in Figure 3, in E. coli and ESKAPE pathogens, resistance to imipenem and meropenem did not vary much during the study period and were lowest among all.

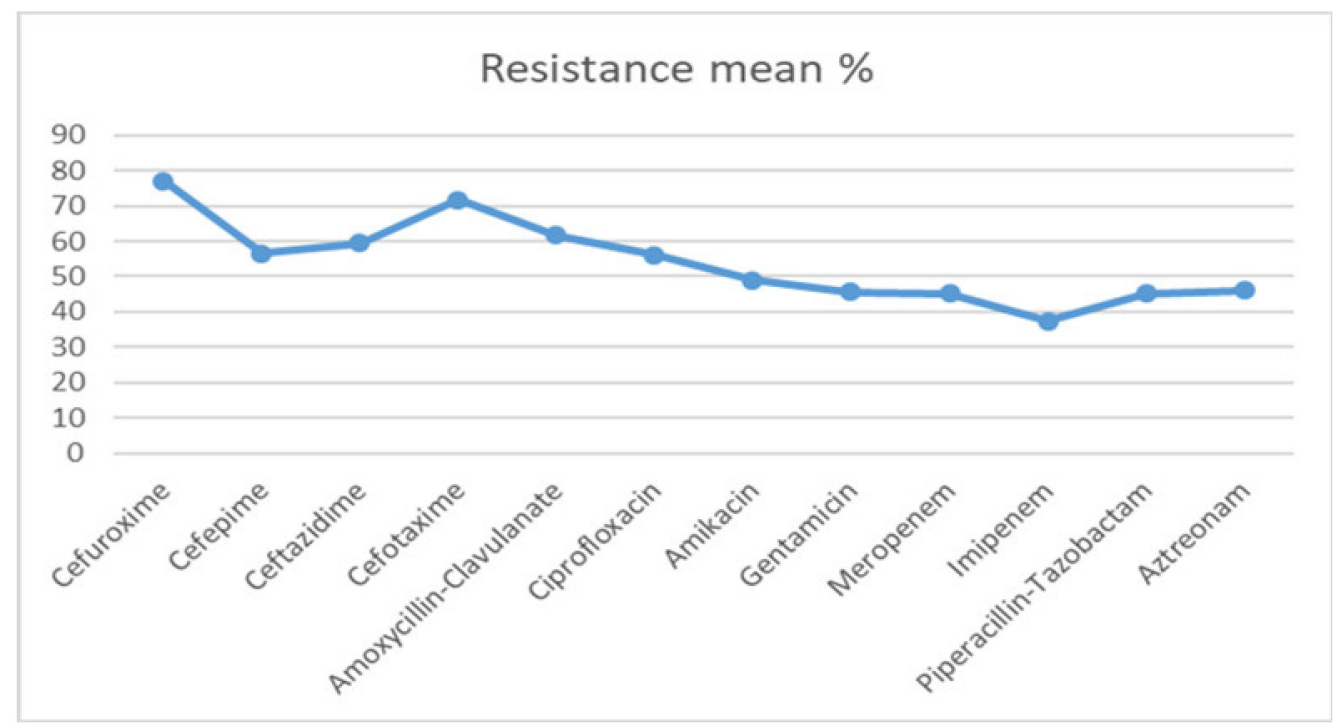

Figure 3. Antibiotic resistance among E. coli and ESKAPE pathogens in the Arab region (mean percentage) during 2000-2020.

Overall, the antibiotic resistance rates in Arab regions are significantly higher than those observed in the USA and Europe. Based on recently published global surveillance studies, SENTRY involving a significantly high proportion of E. coli, K. pneumoniae, P. aeruginosa, S. aureus, Enterobacter and A. baumannii were collected during the years 2013 through 2018 by JMI labs. We compared resistance trends in these nations against Arab nations. Our analyses of antibiotic resistance rates in Arab regions during the study period (2000 to 2020) showed mean values of resistance rates in E. coli to cephalosporins (cefuroxime, ceftazidime, and cefepime) as (85.1\%, 63.8\%, and 66.3\%), respectively, while in the USA they were about $38.5 \%, 11 \%$, and $11.7 \%$, respectively, and in the UK $35.9 \%, 10 \%$, and $11.1 \%$, respectively. In other countries such as Australia, they were $32 \%, 9.1 \%$, and $9.8 \%$, respectively. Considering the resistance to $\beta$-lactam and $\beta$-lactamase inhibitor combinations (amoxicillin-clavulanic acid and piperacillin-tazobactam), it was (58.8\% and $40.1 \%)$, respectively, in Arab nations. However, significantly lower resistance was observed in the US (21.6\% and $4 \%$ ) and UK (27.6\%, and $6.8 \%)$. In developing nations such as China (35\% and 7.9\%) and India (59.6\% and $21.3 \%$ ), these values were relatively higher. Similarly, resistance rates to aminoglycosides such as gentamicin and amikacin were $52.8 \%$ and $43.1 \%$, respectively, in Arabic countries, while in the US they were $12.4 \%$ and $0.3 \%$ and in the UK they were 10.8 and $0.8 \%$, which is significantly lower. In Australia, they were $(8.4 \%$ and $0.2 \%)$, China (54.5\% and 3.4\%) and India (41.3\% and 6.4\%), respectively, while in the US, UK, China and India they reached $32.4 \%, 24.3 \%, 72 \%$ and $72.3 \%$, respectively. Resistance to carbapenems (imipenem and meropenem) in E. coli was $33.6 \%$ and $47.8 \%$, respectively, while in the US and UK it was $0.2 \%$ for both. In Australia, it was remarkably low ( $0.1 \%$ for imipenem and $0 \%$ for meropenem). In China, it was about 
$1.1 \%$ and $0.1 \%$, respectively, and in India, $8.5 \%$ and $8.5 \%$, respectively, [114]. Similar resistance trends were noted in K. pneumoniae in other territories such as the US, and Europe, which were significantly lower than Arabic nations. In K. pneumoniae, cephalosporin resistance in the US and Europe was in the range of $12-31 \%$. However, in Arabic regions, this was significantly higher, at $63-86 \%$. Resistance to aminoglycosides such as amikacin and gentamicin (42-64\%) and carbapenems (27-36\%) was relatively higher in Arabic nations, while in the US and Europe, it was about $2-8 \%$ and $1-4 \%$, respectively. It is important to note that the resistance rates to aminoglycosides and carbapenems in Arabic nations are higher than in India (24-34\% and 29-30\%) and China (11-29\% and 12-13\%) (SENTRY 2013-2018) [114]. Additionally, the mean values of resistance rates in P. aeruginosa to cephalosporins (ceftazidime and cefepime) were $62 \%$ and $58.2 \%$, respectively, in Arabic nations, while in the US they were $15.8 \%$ and $15.2 \%$, respectively, and in the UK they were $10.7 \%$ and $8.2 \%$, respectively. In Australia they were only $12.6 \%$ and $8.3 \%$, respectively, and resistance to $\beta$-lactam and $\beta$-lactamase inhibitor combinations such as piperacillin-tazobactam was $51.2 \%$ in Arabic countries, while it was $19.7 \%$ in the US, $13.7 \%$ in the UK, $15.5 \%$ in Australia, 31.3\% in China and $40.5 \%$ in India. Similarly, the resistance rates to aminoglycosides (gentamicin and amikacin) were $62.6 \%$ and $51.4 \%$ in Arab nations, while in the US they were $14 \%$ and $4 \%$, and in the UK $3.7 \%$ and $1 \%$, respectively. In Australia, they were only $8.1 \%$ and $4.6 \%$, in China $15.2 \%$ and $7.4 \%$, and in India $40.5 \%$ and $27.9 \%$, respectively. The resistance to quinolones (ciprofloxacin) was $58.3 \%$ in Arab nations. In the US, it was $28.2 \%$, UK $12.2 \%$, Australia $14.8 \%$, China $29.6 \%$ and India $43.3 \%$. The resistance to carbapenems (imipenem and meropenem) in P. aeruginosa was $42.6 \%$ and $35.6 \%$, respectively, while in the US and the UK it was much lower $(21.8 \%$ and $19.8 \%$, and $17 \%$ and $15.2 \%$, respectively). In Australia, it was $12 \%$ and $8.6 \%$, respectively, China $33.3 \%$ and $27.7 \%$, respectively, and India $33.4 \%$ and $33.4 \%$, respectively [114]. Therefore, the overall antibiotic resistance to $P$. aeruginosa is quite similar across various geographies owing to the limited therapeutic options available for the treatment of infections caused by these pathogens. Based on the availability of antibiotic susceptibility, combinations of piperacillin-tazobactam or imipenem/meropenem and aminoglycosides are administered for the treatment of these difficult-to-treat pathogens. However, the increasing resistance to these higher antibiotics is a serious threat in hospital settings. Likewise, the mean values of resistance rates in S. aureus to cephalosporins, cefepime was $50 \%$ in Arab countries, while in the USA it was $48 \%, 18.5 \%$ in UK, and $31.4 \%$ in Australia. Resistance to $\beta$-lactam and $\beta$-lactamase inhibitor combinations (amoxicillin-clavulanic acid and piperacillin-tazobactam) affected $50 \%$ and $54.4 \%$ of isolates, respectively, while in the USA it was $48 \%$ and $46.2 \%$, respectively, UK $18.8 \%$ and $16.3 \%$, Australia $31.3 \%$ and $28.1 \%$, China $45.7 \%$ and $45.7 \%$ and India $51.3 \%$ and $51.3 \%$. Similarly, the resistance to quinolones (ciprofloxacin) was 38.3\%, while in the USA, UK, Australia and China; it was $40.6 \%, 19.4 \%$, $17.4 \%$ and $46.9 \%$, respectively. The phenotypic resistance to carbapenems (imipenem and meropenem) in S. aureus were $22.5 \%$ and $25.6 \%$, respectively, while in the US it was $48 \%$ and $48 \%$, respectively, and in the UK $18.4 \%$ and $18.5 \%$, respectively, Australia $31.4 \%$ and $31.4 \%$, respectively, China $45.7 \%$ and 45.7\%, respectively, and India 51.3\% and 51.3\%, respectively (SENTRY 2013-2018) [114]. A. baumannii is another highly challenging pathogen owing to its ability to intrinsically express diverse resistance mechanisms such as highly reduced outer membrane porins and the ability to express the efflux pumps in higher order, leading to insufficient concentration of antibiotics inhibiting the bacterial cell targets. Therefore, antibiotic resistance to A. baumannii is significantly higher around the world. The mean values of resistance rates in A. baumannii to cephalosporins (ceftazidime and cefepime) were $91.3 \%$ and $79 \%$, respectively, while in the USA $45.3 \%$ and $49.9 \%$, respectively, and UK $7.2 \%$ and $21.4 \%$, respectively, Australia $18.8 \%$ and $27.5 \%$, respectively, and $\beta$-lactam and $\beta$-lactamase inhibitor combinations such as piperacillin-tazobactam were $60 \%$, while in the USA, UK, Australia, China and India, they were $52.2 \%, 28.6 \%, 28.1 \%, 82.4 \%$ and $55.6 \%$, respectively. Similarly, resistance rates of aminoglycosides (gentamicin and amikacin) were $73.3 \%$ and $72.2 \%$, while in the US they were $37.9 \%$ and $23.7 \%$, respectively, and in the UK $35.7 \%$ and $14.3 \%$, respectively, Australia $13 \%$ and $8.7 \%$, respectively, China $79.5 \%$ and $72.9 \%$, respectively, and India 50\% and 55.6\%, respectively. Additionally, resistance to quinolones (ciprofloxacin) was $86.4 \%$, while in the US $48.6 \%$ and UK $14.3 \%$, Australia $17.4 \%$, China $79 \%$ 
and India $45.6 \%$. The resistance to carbapenems (imipenem and meropenem) in A. baumannii was $60.7 \%$ and $62.3 \%$, respectively, while in the US it was $39.9 \%$ and $42.2 \%$, respectively, UK $14.3 \%$ and $14.3 \%$, respectively, Australia $8.7 \%$ and $8.7 \%$, respectively, China $75.9 \%$ and $77.7 \%$, respectively, and India 55.6\% and 55.6\%, respectively [114]. Against another clinically important Gram-negative pathogen, Enterobacter spp., resistance to cephalosporins (ceftazidime and cefepime) was $66.8 \%$ and $4.4 \%$, respectively, in Arabic regions, while in the US it was $23 \%$ and $8.4 \%$, respectively, and UK $15.2 \%$ and $5.9 \%$, respectively, Australia $26.2 \%$ and $8 \%$, respectively. Resistance to $\beta$-lactam and $\beta$-lactamase inhibitor combination (piperacillin-tazobactam) was $48 \%$ in the Arab region, while in the US it was $17.8 \%$, UK $8.8 \%$, Australia $23.3 \%$, China $23.3 \%$ and India $0 \%$. Similarly, resistance rates to aminoglycosides (gentamicin and amikacin) in the Arab region were $62.8 \%$ and $41.4 \%$, while in the US they were $4.4 \%$ and $0.3 \%$, respectively, UK $3.5 \%$ and $0 \%$, respectively, Australia $6 \%$ and $0 \%$, respectively, China $16.4 \%$ and $1.4 \%$, respectively, and India $33.3 \%$ and $0 \%$, respectively. Additionally, resistance to quinolones (ciprofloxacin) in the Arab region was 50.4\%, while in the US it was 9.3\%, UK 2.3\%, Australia 6\%, China 26\%, and India 33.3\%. Resistance to carbapenems (imipenem and meropenem) among Enterobacter spp. isolates was $29.4 \%$ and $30.6 \%$, respectively, while in the US it was $2.4 \%$ and $1.8 \%$, respectively, in the UK $2.4 \%$ and $0.6 \%$, respectively, Australia $2.5 \%$ and $1.5 \%$, respectively, China $1.4 \%$ and $1.4 \%$, respectively, and India $0 \%$ and $0 \%$, respectively [114].

Table 4 provides antibiotic resistance trends at 5 -year intervals. It shows a sustained increase in antibiotic resistance rates during the study period (2000-2020). It was low in the first period (2000-2005) and increased in the second period (2006-2010); this increase continued from 2011-2015 and reached the highest peak in the last period 2016-2020. For example, the mean values of resistance rates to cephalosporins (cefuroxime, cefotaxime, ceftazidime and cefepime were $44.6 \%, 62.5 \%, 49 \%$ and $39 \%$ in 2000-2005, which increased to $87.2 \%, 78 \%, 53 \%$ and $47 \%$ in 2006-2010. This increase continued to $89.2 \%, 74.3 \%, 62.8 \%$ and $66.5 \%$ in $2011-2015$ and reached a maximum in the last period of $87.5 \%, 72.5 \%$, $72.3 \%$ and $73.6 \%$ in $2016-2020$, respectively.

Table 4. Antibiotic resistance in E. coli and ESKAPE pathogens during 2000-2020.

\begin{tabular}{ccccc}
\hline Antibiotic & $\begin{array}{c}\mathbf{2 0 0 0 - 2 0 0 5} \\
\text { Mean\% }\end{array}$ & $\begin{array}{c}\mathbf{2 0 0 6 - 2 0 1 0} \\
\text { Mean \% }\end{array}$ & $\begin{array}{c}\mathbf{2 0 1 1 - 2 0 1 5} \\
\text { Mean\% }\end{array}$ & $\begin{array}{c}\mathbf{2 0 1 6 - 2 0 2 0} \\
\text { Mean\% }\end{array}$ \\
\hline Cefuroxime & 44.6 & 87.2 & 89.2 & 87.5 \\
Cefepime & 39 & 47 & 66.5 & 73.6 \\
Ceftazidime & 49 & 53. & 62.8 & 72.3 \\
Cefotaxime & 62.5 & 78.0 & 74.3 & 72.5 \\
Amoxycillin-Clavulanate & 58.6 & 60 & 60.6 & 67.9 \\
Ciprofloxacin & 46.8 & 48.5 & 59.3 & 70.3 \\
Amikacin & 40.2 & 47.3 & 56.9 & 51.4 \\
Gentamicin & 49 & 50.4 & 55.2 & 64.4 \\
Meropenem & 30.5 & & 40.2 & 64.9 \\
Imipenem & 30.9 & & 37.6 & 44.1 \\
Piperacillin-Tazobactam & & 49 & 52.7 & 34.3 \\
Aztreonam & 30.6 & 33.3 & 73.6 & 46.5 \\
\hline
\end{tabular}

Figure 4 shows the geographic distribution of ESBL among E. coli and ESKAPE pathogens in the Arab region (mean percentage). An average of $36.9 \%$ of total isolates were reported to have ESBL phenotypes. However, according to SENTRY antibiotic susceptibility surveillance studies (2013-2018) by JMI labs, the ESBL E. coli rates were very low, and those in the USA, UK and Australia were 15.2\%, $15.2 \%$ and $14.5 \%$, respectively. On the other hand, it was very high in China and India, at $65.8 \%$ and $68 \%$, respectively [114]. 


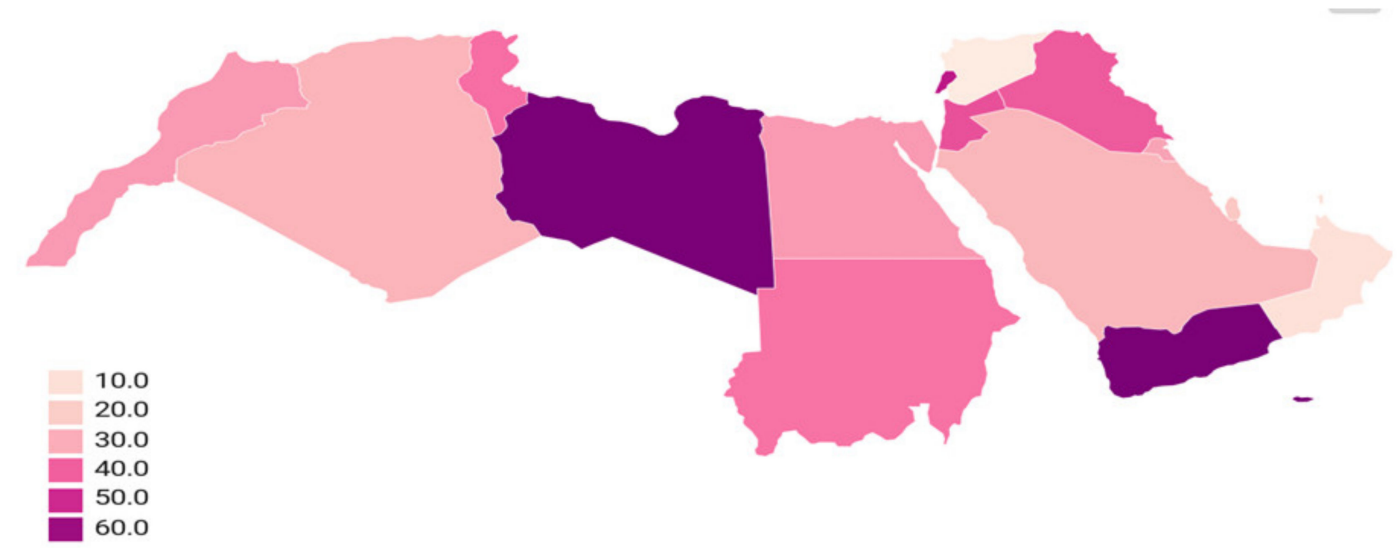

Figure 4. Geography distribution of ESBL among E. coli and ESKAPE pathogens in the Arab region (mean percentage) during 2000-2020.

Figure 5 provides ESBL rates every 5 years, showing a sustained increase in ESBL rates during the study period (2000-2020), it was (mean) $6.9 \%$ in $2000-2005,34.4 \%$ in $2006-2010,33.5 \%$ in $2011-2015$ and $37.1 \%$ in $2016-2020$.

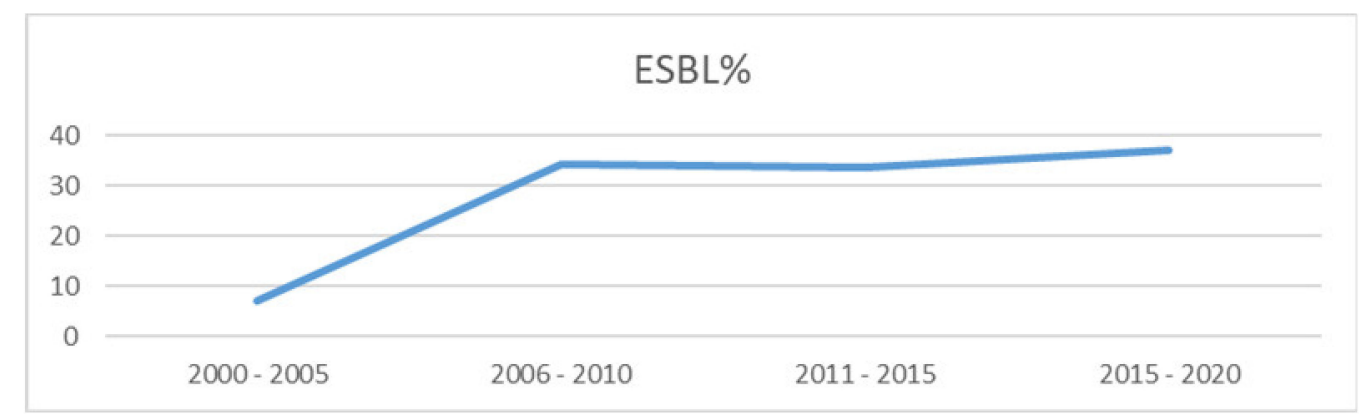

Figure 5. Comparing ESBL producing E. coli and ESKAPE Pathogens during 2000-2020.

The molecular data from the Arab region are abundant enough to suggest that the prevalence of antibiotic resistance among E. coli and ESKAPE pathogens is rising steadily with a predominance of $b^{b} a_{\mathrm{CTX}-\mathrm{M}}$ and bla $_{\mathrm{OXA}}$ of ESBLs (Class A and D) and also bla $a_{\mathrm{VIM}}$ and $b l a_{\mathrm{NDM}}$ of MBLs (Class B) in most countries in the Arab region (Figure 6).

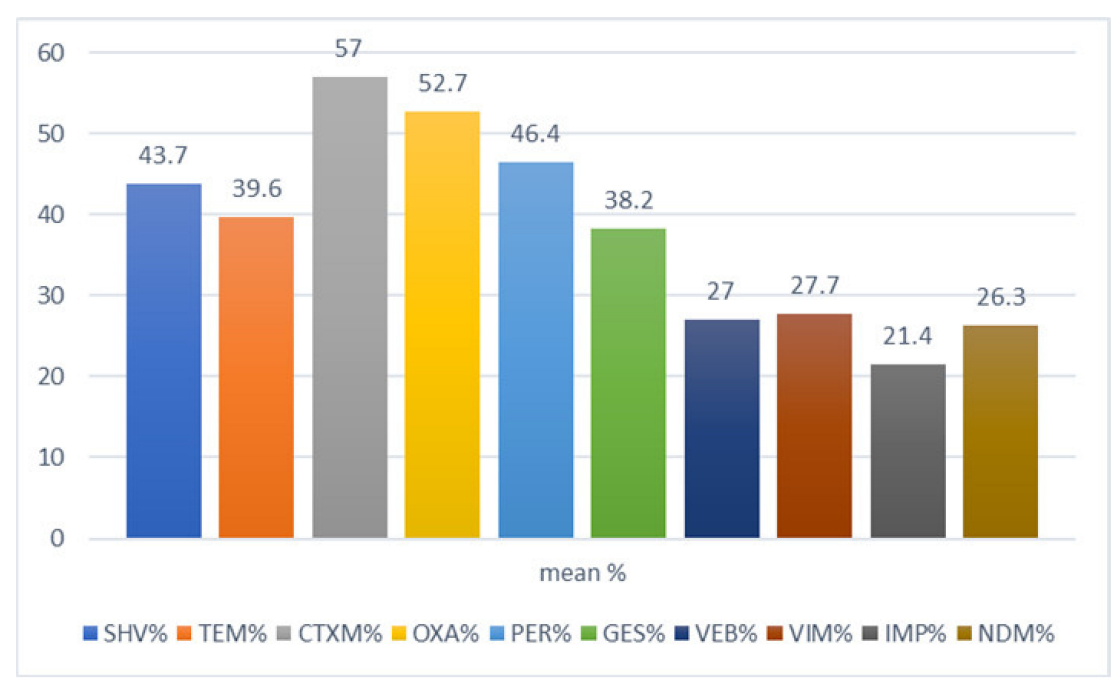

Figure 6. Distribution of $\beta$-lactamase genes among E. coli and ESKAPE pathogens in the Arab region. 
This research indicates the predominance of $b l a_{\mathrm{CTX}-\mathrm{M}}$ and correlates this to bla $a_{\mathrm{CTX}-\mathrm{M}}$ enzymes that have spread globally [115]. Most studies from Arab region countries reported the molecular mechanisms of resistance among E. coli and ESKAPE pathogens. The most commonly produced $\beta$-lactamases were (mean) bla $a_{\mathrm{CTX}-\mathrm{M}} 57 \%$, bla $a_{\mathrm{OXA}} 52.7 \%, b l a_{\mathrm{PER}} 46.4 \%, b l a_{\mathrm{SHV}} 43.7 \%, b l a_{\mathrm{TEM}} 39.6 \%$, $b l a_{\mathrm{GES}} 38.2 \%, b l a_{\mathrm{VEB}} 27 \%$, bla $a_{\mathrm{VIM}} 27.7 \%, b l a_{\mathrm{IMP}} 21.4 \%$ and $b l a_{\mathrm{NDM}} 26.3 \%$. The molecular mechanism of $\beta$-lactamase showed levels sustaining a growing trend through the period of study (2000-2020), as shown in Figure 7.

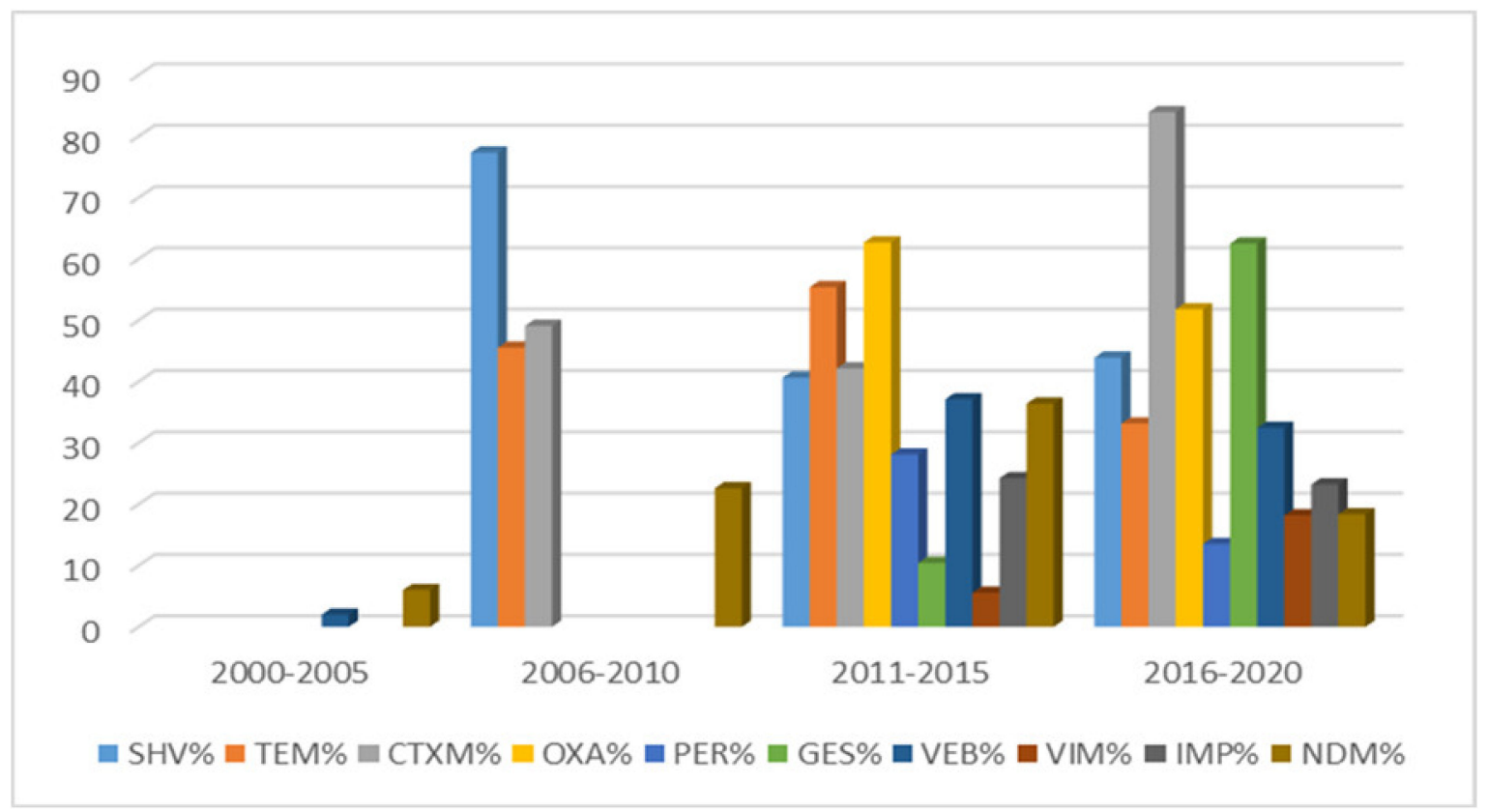

Figure 7. Comparing $\beta$-lactamase genes among E. coli and ESKAPE pathogens in the Arab region during 2000-2020.

These results are consistent with INFORM surveillance studies IHMA that reported CTX-M was the dominant ESBL in Europe with the exception of Greece, where SHV-type ESBLs were more common, with OXA-48 like, NDM and VIM-positive among K. pneumoniae from the European Union countries [116]. High inter-country differences in resistance rates between Arab nations are consistent with those in the European Union, according to the European Antimicrobial Resistance Surveillance Network (EARS-Net) report published in 2016. This report shows large differences in antimicrobial resistance patterns for different countries within the Arab region. Antibiotic resistance in southern and eastern European countries is higher than in north European ones [117]. Curiously, the occurrence of resistant isolates in the Arab region is higher than in other regions in Asia [118]. Overall, all of the Arabic countries showed relatively higher antibiotic resistance expressed in E. coli and Gram-negative ESKAPE pathogens compared to other developing countries such as India and China (SENTRY 2013-2018) [114]. Manifestation of such higher resistance could be due to the lack of access to standard healthcare, exposure to warlike scenarios, hot and dusty climatic factors, unsanitary living conditions and population factors, the status of disease resistance, and also the high prevalence of self-medication with antibiotics. Indeed, Rimah's 2019 Gulf Cooperation Council Countries (GCCC) study revealed that self-medication of antibiotics ranged from $14 \%$ to $73 \%$. Saudi Arabia posted the highest prevalence of self-medication (55\%), followed by Kuwait (28\%), Oman (18\%) and Qatar (14\%).

Based on adherence to antibiotic courses, it was found that a vast majority of patients, $30 \%$ to $72 \%$, who were prescribed antibiotics did not comply [119]. In 2018, Maysun analyzed the attitude and actions of Palestinian refugees attending UNRWA health centers in Jordan concerning antibiotic use, finding that unreasonable antibiotic usage was widespread in $63 \%$ of patients who shared antibiotics at home, and $60 \%$ who bought antibiotics directly from the pharmacy without a 
prescription [120]. Syria's research showed that $57 \%$ of patients used old prescriptions or took advice from someone else [121]. In Yemen, the prevalence of self-medication with antibiotics was 79.1\% [122]. The indiscriminate use of these antibiotics drives selection pressure, enabling the emergence of more and more resistant strains. A word of caution is needed with respect to the use of antibiotics, as the majority of the resistance expressed and spread across various species is due to plasmid-mediated transmission of resistance genes. This study affirms the need for serious measures that are necessary to prevent antibiotic abuse, which would ultimately lead to infection control as well as selection and dissemination of antibiotic resistance. While the data provided in this review on antimicrobial resistance cover the commonly resistant Gram-negative pathogens in the Arab region, they are not dependent on formal national surveillance studies and are collections from the literature published by independent Arab region scientists. Consequently, Enterococcus spp. data were not included due to the limited data available.

Developing countries in the Arab region have poor medical and healthcare facilities, and this could be another potential reason for the prevalence and further spread of antibiotic resistance among E. coli and ESKAPE pathogens. Many developed countries, such as the United States, Europe, Australia, China and India, have their own national surveillance programs, which provide systematic antibiotic susceptibility information. This surveillance data helps clinicians to rationalize the deployment of empiric treatment in a more appropriate way. However, in the absence of such data, irrational use of antibiotics is promoted in developing countries like Arabic regions. Therefore, this study also highlights the need for national surveillance in individual countries in the Arab region, and this strategy should be a priority for national strategic health plans as part of a global antimicrobial resistance containment objective to obtain a clearer and more accurate picture of this situation. These studies were restricted to E. coli and ESKAPE pathogens, rather than Gram-negative bacteria in general, and this could be a limitation; however, these pathogens have been associated with frequent outbreaks and health care associated means of antibiotic resistance. Studies on the emergence and spread of antibiotic resistance from the developed world and developing countries has become essential. Further studies are required to dissect and reason why there is negligible occurrence of Enterococcus faecium in comparison to that in the developed world.

\section{Conclusions}

Increasing incidence of antibiotic resistance has been reported in various countries around the world, particularly in the Arab region. The recent emergence and increase of ESBL strains among E. coli and ESKAPE pathogens in this region is reaching an alarming level. The prevalence of ESBL bacteria is variable throughout the Arab region countries. A high prevalence of ESBL has been reported from most of the Arab region countries. It is particularly high in Libya, with an average of $67.1 \%$, followed by Yemen, with an average of $66.9 \%$, whereas it remains relatively lower in other Arab countries. The resistance appears to be commonly mediated by bla $a_{\mathrm{CTX}-\mathrm{M}}$ in these regions. Additionally, resistance mediated by $b l a_{\mathrm{NDM}}$ was also observed. Additionally, socio-cultural health determinants associated with the structure and conditions of health care systems, as well as health seeking behaviors, are the main factors that influence self-medication with antibiotics. This study illustrates the need for national surveillance in individual countries in the Arab region, and this policy should be a priority for national strategic health plans as a part of the global antimicrobial resistance reduction target to get a better and more accurate picture of this situation

Author Contributions: Conceptualization, A.S.K.; Methodology, M.N.; Software, M.N.; Validation, A.S.K., M.N., R.N.B. and S.P.; Formal Analysis, Supervision M.G.J.F. and A.S.K.; Investigation, M.N. and S.P.; Resources, A.S.K.; Data Curation, S.P. and R.N.B.; Writing-Original Draft Preparation, M.N.; Writing-Review \& Editing, A.S.K. and S.P.; Visualization, M.G.J.F. and A.S.K.; Supervision M.G.J.F. and A.S.K.; Project Administration, A.S.K.; Funding Acquisition, M.G.J.F. All authors have read and agreed to the published version of the manuscript.

Funding: This research received no external funding. 
Acknowledgments: The authors thank all who made the data available and all colleagues for their comments and suggestions. Constructive criticism and comments of anonymous reviewers are gratefully acknowledged.

Conflicts of Interest: The authors declare no conflict of interest.

\section{References}

1. Adedeji, W.A. The Treasure Called Antibiotics. Ann. Ibadan. Postgrad. Med. 2016, 14, 56-57.

2. Spellberg, B.; Taylor-Blake, B. On the exoneration of Dr. William, H. Stewart: Debunking an urban legend. Infect. Dis. Poverty 2013, 2, 3. [CrossRef] [PubMed]

3. Davies, J.; Davies, D. Origins and evolution of antibiotic resistance. Microbiologia 1996, 12, 9-16. [CrossRef] [PubMed]

4. Hancock, R.E.W. Mechanisms of action of newer antibiotics for Gram-positive pathogens. Lancet Infect. Dis. 2005, 5, 209-218. [CrossRef]

5. Neu, H.C. Infections caused by gram-negative pathogens: New clinical considerations. Bull. N. Y. Acad. Med. 1975, 51, 1075-1083. [PubMed]

6. Rice, L.B. Federal Funding for the Study of Antimicrobial Resistance in Nosocomial Pathogens: No ESKAPE. J. Infect. Dis. 2008, 197, 1079-1081. [CrossRef]

7. Founou, R.C.; Founou, L.L.; Essack, S.Y. Clinical and economic impact of antibiotic resistance in developing countries: A systematic review and meta-analysis. PLoS ONE 2017, 12, e0189621. [CrossRef]

8. New Report Calls for Urgent Action to Avert Antimicrobial Resistance Crisis. Available online: https:/www.who.int/news-room/detail/29-04-2019-new-report-calls-for-urgent-action-to-avertantimicrobial-resistance-crisis (accessed on 29 April 2020).

9. WHO. Antimicrobial Resistance; WHO: Pari, France, 2014; Volume 61, ISBN 978-92-4-156474-8.

10. Moher, D.; Liberati, A.; Tetzlaff, J.; Altman, D.G. Preferred Reporting Items for Systematic Reviews and Meta-Analyses: The PRISMA Statement. PLoS Med. 2009, 6, e1000097. [CrossRef]

11. Uz Zaman, T.; Alrodayyan, M.; Albladi, M.; Aldrees, M.; Siddique, M.I.; Aljohani, S.; Balkhy, H.H. Clonal diversity and genetic profiling of antibiotic resistance among multidrug/carbapenem-resistant Klebsiella pneumoniae isolates from a tertiary care hospital in Saudi Arabia. BMC Infect. Dis. 2018, 18, 205. [CrossRef]

12. Elabd, F.M.; Al-Ayed, M.S.Z.; Asaad, A.M.; Alsareii, S.A.; Qureshi, M.A.; Musa,H.A.A. Molecular characterization of oxacillinases among carbapenem-resistant Acinetobacter baumannii nosocomial isolates in a Saudi hospital. J. Infect. Public Health 2015, 8, 242-247. [CrossRef]

13. Ibrahim, M.E.; Abbas, M.; Al-Shahrai, A.M.; Elamin, B.K. Phenotypic Characterization and Antibiotic Resistance Patterns of Extended-Spectrum $\beta$-Lactamase- and AmpC $\beta$-Lactamase-Producing Gram-Negative Bacteria in a Referral Hospital, Saudi Arabia. Can. J. Infect. Dis. Med. Microbiol. = J. Can. Mal. Infec. Microbiol. Med. 2019, 6054694. [CrossRef] [PubMed]

14. Somily, A.M.; Habib, H.A.; Absar, M.M.; Arshad, M.Z.; Manneh, K.; Al Subaie, S.S.; Al Hedaithy, M.A.; Sayyed, S.B.; Shakoor, Z.; Murray, T.S. ESBL-producing Escherichia coli and Klebsiella pneumoniae at a tertiary care hospital in Saudi Arabia. J. Infect. Dev. Ctries. 2014, 8, 1129-1136. [CrossRef] [PubMed]

15. Al-Agamy, M.H.; Shibl, A.M.; Ali, M.S.; Khubnani, H.; Radwan, H.H.; Livermore, D.M. Distribution of $\beta$-lactamases in carbapenem-non-susceptible Acinetobacter baumannii in Riyadh, Saudi Arabia. J. Glob. Antimicrob. Resist. 2014, 2, 17-21. [CrossRef]

16. Al-Agamy, M.H.; Shibl, A.M.; Tawfik, A.F.; Elkhizzi, N.A.; Livermore, D.M. Extended-spectrum and metallo-beta-lactamases among ceftazidime-resistant Pseudomonas aeruginosa in Riyadh, Saudi Arabia. J. Chemother. 2012, 24, 97-100. [CrossRef]

17. Abdalhamid, B.; Hassan, H.; Itbaileh, A.; Shorman, M. Characterization of carbapenem-resistant Acinetobacter baumannii clinical isolates in a tertiary care hospital in Saudi Arabia. New Microbiol. 2014, 37, 65-73. [PubMed]

18. Al-Zahrani, I.A.; Alasiri, B.A. The emergence of carbapenem-resistant Klebsiella pneumoniae isolates producing OXA-48 and NDM in the Southern (Asir) Province, Saudi Arabia. Saudi Med. J. 2018, 39, $23-30$. [CrossRef] [PubMed]

19. Al-Qahtani, A.A.; Al-Agamy, M.H.; Ali, M.S.; Al-Ahdal, M.N.; Aljohi, M.A.; Shibl, A.M. Characterization of extended-spectrum betalactamase-producing klebsiella pneumoniae from Riyadh, Saudi Arabia. J. Chemother. 2014, 26, 139-145. [CrossRef] 
20. Alyamani, E.J.; Khiyami, A.M.; Booq, R.Y.; Majrashi, M.A.; Bahwerth, F.S.; Rechkina, E. The occurrence of ESBL-producing Escherichia coli carrying aminoglycoside resistance genes in urinary tract infections in Saudi Arabia. Ann. Clin. Microbiol. Antimicrob. 2017, 16, 1. [CrossRef]

21. Al-Agamy, M.H.M.; Shibl, A.M.; Tawfik, A.F. Prevalence and molecular characterization of extended-spectrum ß-lactamase-producing Klebsiella pneumoniae in Riyadh, Saudi Arabia. Ann. Saudi Med. 2009, 29, $253-257$. [CrossRef]

22. Kader, A.A.; Kumar, A. Prevalence and antimicrobial susceptibility of extended-spectrum $\beta$-lactamase-producing Escherichia coli and Klebsiella pneumoniae in a general hospital. Ann. Saudi Med. 2005, 25, 239-242. [CrossRef]

23. Yezli, S.; Shibl, A.M.; Livermore, D.M.; Memish, Z.A. Prevalence and antimicrobial resistance among Gram-negative pathogens in Saudi Arabia. J. Chemorther. 2014, 26, 257-272. [CrossRef] [PubMed]

24. Tawfik, A.F.; Alswailem, A.M.; Shibl, A.M.; Al-Agamy, M.H.M. Prevalence and genetic characteristics of TEM, SHV, and CTX-M in clinical Klebsiella pneumoniae isolates from Saudi Arabia. Microb. Drug. Resist. 2011, 17, 383-388. [CrossRef] [PubMed]

25. Al-Agamy, M.H.; Jeannot, K.; El-Mahdy, T.S.; Samaha, H.A.; Shibl, A.M.; Plésiat, P.; Courvalin, P. Diversity of Molecular Mechanisms Conferring Carbapenem Resistance to Pseudomonas aeruginosa Isolates from Saudi Arabia. Can. J. Infect. Dis. Med. Microbiol. 2016, 2016. [CrossRef] [PubMed]

26. Khan, M.A.; Faiz, A. Antimicrobial resistance patterns of Pseudomonas aeruginosa in tertiary care hospitals of Makkah and Jeddah. Ann. Saudi Med. 2016, 36, 23-28. [CrossRef] [PubMed]

27. Hamid, M.E.; Mustafa, F.Y.; Alwaily, A.; Abdelrahman, S.; Al Azragi, T. Prevalence of bacterial pathogens in Aseer region, Kingdom of Saudi Arabia: Emphasis on antimicrobial susceptibility of staphylococcus aureus. Oman Med. J. 2011, 26, 368-370. [CrossRef] [PubMed]

28. Mashwal, F.A.; El Safi, S.H.; George, S.K.; Adam, A.A.; Jebakumar, A.Z. Incidence and molecular characterization of the extended spectrum beta lactamase-producing Escherichia coli isolated from urinary tract infections in Eastern Saudi Arabia. Saudi Med. J. 2017, 38, 811-815. [CrossRef] [PubMed]

29. Al-Garni, S.M.; Ghonaim, M.M.; Ahmed, M.M.M.; Al-Ghamdi, A.S.; Ganai, F.A. Risk factors and molecular features of extended-spectrum beta-lactamase producing bacteria at southwest of Saudi Arabia. Saudi Med. J. 2018, 39, 1186-1194. [CrossRef]

30. Hameed, T.; Al Nafeesah, A.; Chishti, S.; Al Shaalan, M.; Al Fakeeh, K. Community-acquired urinary tract infections in children: Resistance patterns of uropathogens in a tertiary care center in Saudi Arabia. Int. J. Pediatr. Adolesc. Med. 2019, 6, 51-54. [CrossRef]

31. Kader, A.A.; Kumar, A.K. Prevalence of extended spectrum beta-lactamase among multidrug resistant gram-negative isolates from a general hospital in Saudi Arabia. Saudi Med. J. 2004, 25, 570-574.

32. Ahmad, S.; Al-Juaid, N.F.; Alenzi, F.Q.; Mattar, E.H.; Bakheet, O.E.S. Prevalence, antibiotic susceptibility pattern and production of extended-spectrum $\beta$-lactamases amongst clinical isolates of Klebsiella pneumoniae at Armed Forces Hospital in Saudi Arabia. J. Coll. Phys. Surg. Pak. 2009, 19, 264-265.

33. Marie, M.A.; John, J.; Krishnappa, L.G.; Gopalkrishnan, S. Molecular characterization of the $\beta$-lactamases in Escherichia coli and Klebsiella pneumoniae from a tertiary care hospital in Riyadh, Saudi Arabia. Microbiol. Immunol. 2013, 57, 805-810. [CrossRef] [PubMed]

34. Aly, M.M.; Abu Alsoud, N.M.; Elrobh, M.S.; Al Johani, S.M.; Balkhy, H.H. High prevalence of the PER-1 gene among carbapenem-resistant Acinetobacter baumannii in Riyadh, Saudi Arabia. Eur. J. Clin. Microbiol. Infect. Dis. 2016, 35, 1759-1766. [CrossRef] [PubMed]

35. Bindayna, K.M.; Khanfar, H.S.; Senok, A.C.; Botta, G.A. Predominance of CTX-M genotype among extended spectrum beta lactamase isolates in a tertiary hospital in Saudi Arabia. Saudi Med. J. 2010, 31, 859-863.

36. Azim, N.S.A.; Nofal, M.Y.; Alharbi, M.A.; Al-Zaban, M.I.; Somily, A.M. Molecular-diversity, prevalence and antibiotic susceptibility of pathogenic klebsiella pneumoniae under Saudi condition. Pak. J. Biol. Sci. 2019, 22, 174-179. [CrossRef] [PubMed]

37. Farah, S.M.; Alshehri, M.A.; Alfawaz, T.S.; Alasmeri, F.A.; Alageel, A.A.; Alshahrani, D.A. Trends in antimicrobial susceptibility patterns in King Fahad Medical City, Riyadh, Saudi Arabia. Saudi Med. J. 2019, 40, 252-259. [CrossRef]

38. Ranjan Dash, N.; Albataineh, M.T.; Alhourani, N.; Khoudeir, A.M.; Ghanim, M.; Wasim, M.; Mahmoud, I. Community-acquired urinary tract infections due to extended-spectrum $\beta$-lactamase-producing organisms in United Arab Emirates. Travel Med. Infect. Dis. 2018, 22, 46-50. [CrossRef] 
39. Dash, N.; Panigrahi, D.; Zarouni, M.A.; Darwish, D.; Ghazawi, A.; Sonnevend, A.; Pal, T.; Yasin, F.; Hadi, S. Al High Incidence of New Delhi Metallo-Beta-Lactamase-Producing Klebsiella pneumoniae Isolates in Sharjah, United Arab Emirates. Microb. Drug Resist. 2014, 20, 52-56. [CrossRef]

40. Al-Zarouni, M.; Senok, A.; Rashid, F.; Al-Jesmi, S.M.; Panigrahi, D. Prevalence and antimicrobial susceptibility pattern of extended-spectrum beta-lactamase-producing enterobacteriaceae in the United Arab Emirates. Med. Princ. Pract. 2008, 17, 32-36. [CrossRef]

41. Alfaresi, M.S.; Elkoush, A.A.; Alshehhi, H.M.; Abdulsalam, A.I. Molecular characterization and epidemiology of extended-spectrum beta-lactamase-producing escherichia coli and klebsiella pneumoniae isolates in the United Arab Emirates. Med. Princ. Pract. 2011, 20, 177-180. [CrossRef]

42. Moubareck, C.A.; Mouftah, S.F.; Pál, T.; Ghazawi, A.; Halat, D.H.; Nabi, A.; AlSharhan, M.A.; AlDeesi, Z.O.; Peters, C.C.; Celiloglu, H.; et al. Clonal emergence of Klebsiella pneumoniae ST14 co-producing OXA-48-type and NDM carbapenemases with high rate of colistin resistance in Dubai, United Arab Emirates. Int. J. Antimicrob. Agents. 2018, 52, 90-95. [CrossRef]

43. Abdulwahab, A.; Zahraldin, K.; Sid Ahmed, M.A.; Jarir, S.A.; Muneer, M.; Mohamed, S.F.; Hamid, J.M.; Hassan, A.A.I.; Ibrahim, E.B. The emergence of multidrug-resistant Pseudomonas aeruginosa in cystic fibrosis patients on inhaled antibiotics. Lung India 2017, 34, 527-531. [CrossRef] [PubMed]

44. Sid Ahmed, M.A.; Bansal, D.; Acharya, A.; Elmi, A.A.; Hamid, J.M.; Sid Ahmed, A.M.; Chandra, P.; Ibrahim, E.; Sultan, A.A.; Doiphode, S.; et al. Antimicrobial susceptibility and molecular epidemiology of extended-spectrum beta-lactamase-producing Enterobacteriaceae from intensive care units at Hamad Medical Corporation, Qatar. Antimicrob. Resist. Infect. Control. 2016, 5, 4. [CrossRef] [PubMed]

45. AbdulWahab, A.; Taj-Aldeen, S.J.; Ibrahim, E.; Abdulla, S.H.; Muhammed, R.; Ahmed, I.; Abdeen, Y.; Sadek, O.; Abu-Madi, M. Genetic relatedness and host specificity of Pseudomonas aeruginosa isolates from cystic fibrosis and non-cystic fibrosis patients. Infect. Drug. Resist. 2014, 7, 309-316. [CrossRef] [PubMed]

46. Eltai, N.O.; Al Thani, A.A.; Al-Ansari, K.; Deshmukh, A.S.; Wehedy, E.; Al-Hadidi, S.H.; Yassine, H.M. Molecular characterization of extended spectrum $\beta$-lactamases enterobacteriaceae causing lower urinary tract infection among pediatric population. Antimicrob. Resist. Infect. Control. 2018, 7, 90. [CrossRef]

47. Eltai, N.O.; Yassine, H.M.; Al Thani, A.A.; Abu Madi, M.A.; Ismail, A.; Ibrahim, E.; Alali, W.Q. Prevalence of antibiotic resistant Escherichia coli isolates from fecal samples of food handlers in Qatar. Antimicrob. Resist. Infect. Control 2018, 7, 78. [CrossRef] [PubMed]

48. Rolain, J.M.; Loucif, L.; Al-Maslamani, M.; Elmagboul, E.; Al-Ansari, N.; Taj-Aldeen, S.; Shaukat, A.; Ahmedullah, H.; Hamed, M. Emergence of multidrug-resistant Acinetobacter baumannii producing OXA-23 Carbapenemase in Qatar. New Microbes New Infect. 2016, 11, 47-51. [CrossRef]

49. Bonnin, R.A.; Rotimi, V.O.; Al Hubail, M.; Gasiorowski, E.; Al Sweih, N.; Nordmann, P.; Poirela, L. Wide dissemination of GES-type carbapenemases in Acinetobacter baumannii isolates in Kuwait. Antimicrob. Agents Chemother. 2013, 57, 183-188. [CrossRef]

50. Jamal, W.Y.; Albert, M.J.; Rotimi, V.O. High prevalence of New Delhi metallo- $\beta$-lactamase-1 (NDM-1) producers among carbapenem-resistant Enterobacteriaceae in Kuwait. PLoS ONE 2016, 11, e0152638. [CrossRef]

51. Dimitrov, T.S.; Udo, E.E.; Awni, F.; Emara, M.; Passadilla, R. Etiology and antibiotic susceptibility patterns of community-acquired urinary tract Infections in a Kuwait Hospital. Med. Princ. Pract. 2004, 13, 334-339. [CrossRef]

52. Mokaddas, E.M.; Abdulla, A.A.; Shati, S.; Rotimi, V.O. The technical aspects and clinical significance of detecting extended-spectrum $\beta$-lactamase-producing Enterobacteriaceae at a tertiary-care hospital in Kuwait. J. Chemother. 2008, 20, 445-451. [CrossRef]

53. Ensor, V.M.; Jamal, W.; Rotimi, V.O.; Evans, J.T.; Hawkey, P.M. Predominance of CTX-M-15 extended spectrum $\beta$-lactamases in diverse Escherichia coli and Klebsiella pneumoniae from hospital and community patients in Kuwait. Int. J. Antimicrob. Agents 2009, 33, 487-489. [CrossRef] [PubMed]

54. Poirel, L.; Carbonnelle, E.; Bernabeu, S.; Gutmann, L.; Rotimi, V.; Nordmann, P. Importation of OXA-48-producing Klebsiella pneumoniae from Kuwait. J. Antimicrob. Chemother. 2012, 67, 2051-2052. [CrossRef] [PubMed]

55. Poirel, L.; Rotimi, V.O.; Mokaddas, E.M.; Karim, A.; Nordmann, P. VEB-1-like Extended-Spectrum B-Lactamases in Pseudomonas aeruginosa, Kuwait. Emerg. Infect. Dis. 2001, 7, 468-470. [CrossRef] [PubMed] 
56. Udo, E.E.; Al-Lawati, B.A.H.; Al-Muharmi, Z.; Thukral, S.S. Genotyping of methicillin-resistant Staphylococcus aureus in the Sultan Qaboos University Hospital, Oman reveals the dominance of Panton-Valentine leucocidin-negative ST6-IV/t304 clone. New Microbes New Infect. 2014, 2, 100-105. [CrossRef]

57. Al-Lawati, A.M.; Crouch, N.D.; Elhag, K.M. Antibiotic consumption and development of resistance among gram-negative bacilli in intensive care units in Oman. Ann. Saudi Med. 2000, 20, 324-327. [CrossRef]

58. Al Muharrmi, Z.; Rafay, A.M.; Balkhair, A.; Al-Tamemi, S.; Al Mawali, A.; Al Sadiri, H. Extended-spectrum $\beta$-lactamase (ESBL) in Omani Children: Study of prevalence, risk factors and clinical outcomes at Sultan Qaboos University Hospital, Sultanate of Oman. Sultan Qaboos Univ. Med. J. 2008, 8, 171-177.

59. Dortet, L.; Poirel, L.; Al Yaqoubi, F.; Nordmann, P. NDM-1, OXA-48 and OXA-181 carbapenemase-producing Enterobacteriaceae in Sultanate of Oman. Clin. Microbiol. Infect. 2012, 18, E144-E148. [CrossRef]

60. Joji, R.M.; Al-Rashed, N.; Saeed, N.K.; Bindayna, K.M. Detection of VIM and NDM-1 metallo-beta-lactamase genes in carbapenem-resistant Pseudomonas aeruginosa clinical strains in Bahrain. J. Lab. Physicians 2019, 11, 138-143. [CrossRef]

61. Bindayna, K.M.; Senok, A.C.; Jamsheer, A.E. Prevalence of extended-spectrum beta-lactamase-producing Enterobacteriaceae in Bahrain. J. Infect. Public Health 2009, 2, 129-135. [CrossRef]

62. Bindayna, K.M.; Murtadha, M. High prevalence of blaCTX-M in Enterobacteriaceae isolates from the Kingdom of Bahrain. Asian Pac. J. Trop. Med. 2011, 4, 937-940. [CrossRef]

63. Gharout-Sait, A.; Alsharapy, S.A.; Brasme, L.; Touati, A.; Kermas, R.; Bakour, S.; Guillard, T.; de Champs, C. Enterobacteriaceae isolates carrying the New Delhi metallo- $\beta$-lactamase gene in Yemen. J. Med. Microbiol. 2014, 63, 1316-1323. [CrossRef] [PubMed]

64. Nasher, S.; Alsharapy, S.; Al-Madhagi, A.; Zakham, F. Epidemiology of extended-spectrum $\beta$-lactamase producing escherichia coli from hospital settings in yemen. J. Infect. Dev. Ctries. 2018, 12, 953-959. [CrossRef] [PubMed]

65. Bakour, S.; Alsharapy, S.A.; Touati, A.; Rolain, J.M. Characterization of acinetobacter baumannii clinical isolates carrying blaOXA-23 carbapenemase and 16S rRNA methylase armA genes in Yemen. Microb. Drug Resist. 2014, 20, 604-609. [CrossRef] [PubMed]

66. Wolterlink-Van Loo, S.; Siemerink, M.A.J.; Perrakis, G.; Kaper, T.; Kengen, S.W.M.; Van der Oost, J. Improving low-temperature activity of Sulfolobus acidocaldarius 2-keto-3-deoxygluconate aldolase. Archaea 2009, 2, 233-239. [CrossRef]

67. Al-Jamei, S.A.; Albsoul, A.Y.; Bakri, F.G.; Al-Bakri, A.G. Extended-spectrum $\beta$-lactamase producing E. coli in urinary tract infections: A two-center, cross-sectional study of prevalence, genotypes and risk factors in Amman, Jordan. J. Infect. Public Health 2019, 12, 21-25. [CrossRef]

68. Al Dawodeyah, H.Y.; Obeidat, N.; Abu-Qatouseh, L.F.; Shehabi, A.A. Antimicrobial resistance and putative virulence genes of Pseudomonas aeruginosa isolates from patients with respiratory tract infection. Germs 2018, 8, 31-40. [CrossRef]

69. Aqel, A.A.; Giakkoupi, P.; Alzoubi, H.; Masalha, I.; Ellington, M.J.; Vatopoulos, A. Detection of OXA-48-like and NDM carbapenemases producing Klebsiella pneumoniae in Jordan: A pilot study. J. Infect. Public Health 2017, 10, 150-155. [CrossRef]

70. Ronat, J.B.; Kakol, J.; Khoury, M.N.; Berthelot, M.; Yun, O.; Brown, V.; Murphy, R.A. Highly drug-resistant pathogens implicated in burn-associated bacteremia in an Iraqi burn care unit. PLoS ONE 2014, 9, e101017. [CrossRef]

71. Al-Charrakh, A.H.; Al-Awadi, S.J.; Mohammed, A.S. Detection of Metallo- $\beta$-Lactamase Producing Pseudomonas aeruginosa Isolated from Public and Private Hospitals in Baghdad, Iraq. Acta Med. Iran. 2016, 54, 107-113.

72. Van Burgh, S.; Maghdid, D.M.; Ganjo, A.R.; Mansoor, I.Y.; Kok, D.J.; Fatah, M.H.; Alnakshabandi, A.A.; Asad, D.; Hammerum, A.M.; Ng, K.; et al. PME and Other ESBL-Positive Multiresistant Pseudomonas aeruginosa Isolated from Hospitalized Patients in the Region of Kurdistan, Iraq. Microb. Drug Resist. 2019, 25, 32-38. [CrossRef]

73. Majeed, H.T.; Aljanaby, A.A.J. Antibiotic Susceptibility Patterns and Prevalence of Some Extended Spectrum Beta-Lactamases Genes in Gram-Negative Bacteria Isolated from Patients Infected with Urinary Tract Infections in Al-Najaf City, Iraq. Avicenna J. Med. Biotechnol. 2019, 11, 192-201. [PubMed] 
74. Hussein, N.H. Emergence of NDM-1 among carbapenemresistant klebsiella pneumoniae in Iraqi hospitals. Acta Microbiol. Immunol. Hung. 2018, 65, 211-227. [CrossRef] [PubMed]

75. Hamzeh, A.R.; Al Najjar, M.; Mahfoud, M. Prevalence of antibiotic resistance among Acinetobacter baumannii isolates from Aleppo, Syria. Am. J. Infect. Control 2012, 40, 776-777. [CrossRef]

76. Al-Assil, B.; Mahfoud, M.; Hamzeh, A.R. Resistance trends and risk factors of extended spectrum $\beta$-lactamases in Escherichia coli infections in Aleppo, Syria. Am. J. Infect. Control 2013, 41, 597-600. [CrossRef] [PubMed]

77. Samaha-Kfoury, J.N.; Kanj, S.S.; Araj, G.F. In vitro activity of antimicrobial agents against extended-spectrum $\beta$-lactamase-producing Escherichia coli and Klebsiella pneumoniae at a tertiary care center in Lebanon. Am. J. Infect. Control 2005, 33, 134-136. [CrossRef] [PubMed]

78. Obeid Charrouf, F.; Hamze, M.; Mallat, H.; Achkar, M.; Dabboussi, F. Characterization of resistance genes in 68ESBL-producing Klebsiella pneumonia in Lebanon. Med. Mal. Infect. 2014, 44, 535-538. [CrossRef]

79. Dahdouh, E.; Hajjar, M.; Suarez, M.; Daoud, Z. Acinetobacter baumannii isolated from lebanese patients: Phenotypes and genotypes of resistance, clonality, and determinants of pathogenicity. Front. Cell. Infect. Microbiol. 2016, 25, 163. [CrossRef] [PubMed]

80. Arabaghian, H.; Salloum, T.; Alousi, S.; Panossian, B.; Araj, G.F.; Tokajian, S. Molecular Characterization of Carbapenem Resistant Klebsiella pneumoniae and Klebsiella quasipneumoniae Isolated from Lebanon. Sci. Rep. 2019, 9, 531. [CrossRef]

81. Yaghi, J.; Fattouh, N.; Akkawi, C.; El Chamy, L.; Maroun, R.G.; Khalil, G. Unusually High Prevalence of Cosecretion of Ambler Class A and B Carbapenemases and Nonenzymatic Mechanisms in Multidrug-Resistant Clinical Isolates of Pseudomonas aeruginosa in Lebanon. Microb. Drug Resist. 2020, 26, 150-159. [CrossRef]

82. Tayh, G.; Al Laham, N.; Ben Yahia, H.; Ben Sallem, R.; Elotto, A.E.; Ben Slamm, K. Extended-Spectrum $\beta$-Lactamases Among Enterobacteriaceae Isolated From Urinary Tract Infections in Gaza Strip, Palestine. Biomed. Res. Int. 2019, 2019, 4041801. [CrossRef]

83. Adwan, K.; Jarrar, N.; Abu-Hijleh, A.; Adwan, G.; Awwad, E. Molecular characterization of Escherichia coli isolates from patients with urinary tract infections in Palestine. J. Med. Microbiol. 2014, 63, 229-234. [CrossRef] [PubMed]

84. Gaballah, A.; Elbaradei, A.; Elsheredy, A.; Kader, O. Emergence of blaveB and blages among VIM-producing Pseudomonas aeruginosa clinical isolates in Alexandria, Egypt. Acta Microbiol. Immunol. Hung. 2019, 66, 131-142. [CrossRef] [PubMed]

85. El-Shouny, W.A.; Ali, S.S.; Sun, J.; Samy, S.M.; Ali, A. Drug resistance profile and molecular characterization of extended spectrum beta-lactamase (ES $\beta$ L)-producing Pseudomonas aeruginosa isolated from burn wound infections. Essential oils and their potential for utilization. Microb. Pathog. 2018, 116, 301-312. [CrossRef] [PubMed]

86. Hashem, H.; Hanora, A.; Abdalla, S.; Shaeky, A.; Saad, A. Dissemination of metallo- $\beta$-lactamase in Pseudomonas aeruginosa isolates in Egypt: Mutation in bla VIM-4. Apmis 2017, 125, 499-505. [CrossRef]

87. Zorgani, A.; Daw, H.; Sufya, N.; Bashein, A.; Elahmer, O.; Chouchani, C. Co-Occurrence of Plasmid-Mediated AmpC $\beta$-Lactamase Activity Among Klebsiella pneumoniae and Escherichia Coli. Open Microbiol. J. 2017, 11, 195-202. [CrossRef]

88. Kamel, N.A.; El-tayeb, W.N.; El-Ansary, M.R.; Mansour, M.T.; Aboshanab, K.M. Phenotypic screening and molecular characterization of carbapenemase-producing Gram-negative bacilli recovered from febrile neutropenic pediatric cancer patients in Egypt. PLoS ONE 2018, 13, e0202119. [CrossRef]

89. Al Yousef, S.A.; Younis, S.; Farrag, E.; Moussa, H.S.; Bayoumi, F.S.; Ali, A.M. Clinical and laboratory profile of urinary tract infections associated with extended spectrum $B$-lactamase producing Escherichia coli and Klebsiella pneumoniae. Ann. Clin. Lab. Sci. 2016, 46, 393-400.

90. Al-Agamy, M.H.; Khalaf, N.G.; Tawfick, M.M.; Shibl, A.M.; El Kholy, A.A. Molecular characterization of carbapenem-insensitive Acinetobacter baumannii in Egypt. Int. J. Infect. Dis. 2014, 22, 49-54. [CrossRef]

91. Zafer, M.M.; Al-Agamy, M.H.; El-Mahallawy, H.A.; Amin, M.A.; Ashour, M.S.E.D. Antimicrobial resistance pattern and their beta-lactamase encoding genes among Pseudomonas aeruginosa strains isolated from cancer patients. Biomed. Res. Int. 2014, 101635. [CrossRef]

92. Abdallah, H.M.; Wintermans, B.B.; Reuland, E.A.; Koek, A.; Al Naiemi, N.; Ammar, A.M.; Mohamed, A.A.; Vandenbroucke-Grauls, C.M.J.E. Extended-spectrum $\beta$-lactamase- and carbapenemase-producing enterobacteriaceae isolated from Egyptian patients with suspected blood stream infection. PLoS ONE 2015, 10, e0136052. [CrossRef] 
93. Abbas, H.A.; El-Ganiny, A.M.; Kamel, H.A. Phenotypic and genotypic detection of antibiotic resistance of Pseudomonas aeruginosa isolated from urinary tract infections. Afr. Health Sci. 2018, 18, 11-21. [CrossRef]

94. Mathlouthi, N.; Al-Bayssari, C.; El Salabi, A.; Bakour, S.; Ben Gwierif, S.; Zorgani, A.A.; Jridi, Y.; Ben Slama, K.; Rolain, J.M.; Chouchani, C. Carbapenemases and extended-spectrum $\beta$-lactamases producing enterobacteriaceae isolated from Tunisian and Libyan hospitals. J. Infect. Dev. Ctries. 2016, 10, 718-727. [CrossRef] [PubMed]

95. Messai, Y.; Iabadene, H.; Benhassine, T.; Alouache, S.; Tazir, M.; Gautier, V.; Arlet, G.; Bakour, R. Prevalence and characterization of extended-spectrum $\beta$-lactamases in Klebsiella pneumoniae in Algiers hospitals (Algeria). Pathol. Biol. 2008, 56, 319-325. [CrossRef] [PubMed]

96. Nedjai, S.; Barguigua, A.; Djahmi, N.; Jamali, L.; Zerouali, K.; Dekhil, M.; Timinouni, M. Prevalence and characterization of extended spectrum beta-lactamase-producing Enterobacter cloacae strains in Algeria. J. Infect. Dev. Ctries. 2013, 7, 804-811. [CrossRef] [PubMed]

97. Nabti, L.Z.; Sahli, F.; Radji, N.; Mezaghcha, W.; Semara, L.; Aberkane, S.; Lounnas, M.; Solassol, J.; Didelot, M.N.; Jean-Pierre, H.; et al. High Prevalence of Multidrug-Resistant Escherichia coli in Urine Samples from Inpatients and Outpatients at a Tertiary Care Hospital in Sétif, Algeria. Microb. Drug Resist. 2019, 25, 386-393. [CrossRef] [PubMed]

98. Baba Ahmed-Kazi Tani, Z.; Decré, D.; Genel, N.; Boucherit-Otmani, Z.; Arlet, G.; Drissi, M. Molecular and epidemiological characterization of enterobacterial multidrug-resistant strains in Tlemcen Hospital (Algeria) (2008-2010). Microb. Drug Resist. 2013, 19, 185-190. [CrossRef] [PubMed]

99. Touati, M.; Diene, S.M.; Dekhil, M.; Djahoudi, A.; Racherache, A.; Rolain, J.M. Dissemination of a class i integron carrying VIM-2 carbapenemase in Pseudomonas Aeruginosa clinical isolates from a hospital intensive care unit in annaba Algeria. Antimicrob. Agents Chemother. 2013, 57, 2426-2427. [CrossRef] [PubMed]

100. Dziri, O.; Dziri, R.; Maraoub, A.; Chouchani, C. First report of SHV-148-Type ESBL and CMY-42-type AmpC $\beta$-lactamase in klebsiella pneumoniae clinical isolates in Tunisia. Microb. Drug. Resist. 2018, 24, 1483-1488. [CrossRef]

101. Ben Tanfous, F.; Achour, W.; Raddaoui, A.; Ben Hassen, A. Molecular characterisation and epidemiology of extended-spectrum $\beta$-lactamase-producing Klebsiella pneumoniae isolates from immunocompromised patients in Tunisia. J. Glob. Antimicrob. Resist. 2018, 13, 154-160. [CrossRef]

102. Elhani, D.; Bakir, L.; Aouni, M.; Passet, V.; Arlet, G.; Brisse, S.; Weill, F.X. Molecular epidemiology of extended-spectrum $\beta$-lactamase-producing Klebsiella pneumoniae strains in a university hospital in Tunis, Tunisia, 1999-2005. Clin. Microbiol. Infect. 2010, 16, 157-164. [CrossRef]

103. Ben Sallem, R.; Ben Slama, K.; Estepa, V.; Jouini, A.; Gharsa, H.; Klibi, N.; Sáenz, Y.; Ruiz-Larrea, F.; Boudabous, A.; Torres, C. Prevalence and characterisation of extended-spectrum beta-lactamase (ESBL)-producing Escherichia coli isolates in healthy volunteers in Tunisia. Eur. J. Clin. Microbiol. Infect. Dis. 2012, 31, 1511-1516. [CrossRef] [PubMed]

104. Mechergui, A.; Achour, W.; Mathlouthi, S.; Hassen, A.B. Prevalence of infectious multi-drug resistant bacteria isolated from immunocompromised patients in Tunisia. Afr. Health Sci. 2019, 19, 2021-2025. [CrossRef] [PubMed]

105. Jaidane, N.; Naas, T.; Oueslati, S.; Bernabeu, S.; Boujaafar, N.; Bouallegue, O.; Bonnin, R.A. Whole-genome sequencing of NDM-1-producing ST85 Acinetobacter baumannii isolates from Tunisia. Int. J. Antimicrob. Agents 2018, 52, 916-921. [CrossRef] [PubMed]

106. Maroui, I.; Barguigua, A.; Aboulkacem, A.; Ouarrak, K.; Sbiti, M.; Louzi, H.; Timinouni, M.; Belhaj, A. First report of VIM-2 metallo- $\beta$-lactamases producing Pseudomonas aeruginosa isolates in Morocco. J. Infect. Chemother. 2016, 22, 127-132. [CrossRef]

107. Bourjilat, F.; Bouchrif, B.; Dersi, N.; Claude, J.D.P.G.; Amarouch, H.; Timinouni, M. Emergence of extended-spectrum beta-lactamase-producing Escherichia coli in community-acquired urinary infections in Casablanca, Morocco. J. Infect. Dev. Ctries. 2011, 5, 850-855. [CrossRef] [PubMed]

108. Arhoune, B.; Oumokhtar, B.; Hmami, F.; Barguigua, A.; Timinouni, M.; el Fakir, S.; Chami, F.; Bouharrou, A. Rectal carriage of extended-spectrum $\beta$-lactamase- and carbapenemase-producing Enterobacteriaceae among hospitalised neonates in a neonatal intensive care unit in Fez, Morocco. J. Glob. Antimicrob. Resist. 2017, 8, 90-96. [CrossRef] 
109. Girlich, D.; Bouihat, N.; Poirel, L.; Benouda, A.; Nordmann, P. High rate of faecal carriage of extended-spectrum $\beta$-lactamase and OXA-48 carbapenemase-producing Enterobacteriaceae at a University hospital in Morocco. Clin. Microbiol. Infect. 2014, 20, 350-354. [CrossRef]

110. Mohammed, I.; Abass, E. Phenotypic detection of Extended Spectrum $\beta$-Lactamases (ESBL) among gram negative uropathogens reveals highly susceptibility to imipenem. Pak. J. Med. Sci. 2019, 35, 1104-1109. [CrossRef]

111. Ibrahim, M.E.; Bilal, N.E.; Magzoub, M.A.; Hamid, M.E. Prevalence of extended-spectrum $\beta$-lactamases-producing Escherichia coli from hospitals in Khartoum State, Sudan. Oman. Med. J. 2013, 28, 116-120. [CrossRef]

112. Adam, M.A.; Elhag, W.I. Prevalence of metallo- $\beta$-lactamase acquired genes among carbapenems susceptible and resistant Gram-negative clinical isolates using multiplex PCR, Khartoum hospitals, Khartoum Sudan. BMC Infect. Dis. 2018, 18, 668. [CrossRef]

113. Plantamura, J.; Bousquet, A.; Védy, S.; Larréché, S.; Bigaillon, C.; Delacour, H.; Mérens, A. Molecular epidemiological of extended-spectrum $\beta$-lactamase producing Escherichia coli isolated in Djibouti. J. Infect. Dev. Ctries 2019, 13, 753-758. [CrossRef] [PubMed]

114. SENTRY 2013-2018 JMI MVP. Available online: https://sentry-mvp.jmilabs.com/app/sentry-public/heatmap (accessed on 13 May 2020).

115. Cantón, R.; González-Alba, J.M.; Galán, J.C. CTX-M enzymes: Origin and diffusion. Front. Microbiol. 2012, 3 , 110. [CrossRef] [PubMed]

116. Kazmierczak, K.M.; de Jonge, B.L.M.; Stone, G.G.; Sahm, D.F. Longitudinal analysis of ESBL and carbapenemase carriage among Enterobacterales and Pseudomonas aeruginosa isolates collected in Europe as part of the International Network for Optimal Resistance Monitoring (INFORM) global surveillance programme, 2013-2017. J. Antimicrob. Chemother. 2020, 75, 1165-1173. [CrossRef] [PubMed]

117. Antimicrobial Resistance Surveillance in Europe. 2016. Available online: https://www.ecdc.europa.eu/en/ publications-data/antimicrobial-resistance-surveillance-europe-2016 (accessed on 25 March 2020).

118. Xu, Y.; Gu, B.; Huang, M.; Liu, H.; Xu, T.; Xia, W.; Wang, T. Epidemiology of carbapenem resistant Enterobacteriaceae (CRE) during 2000-2012 in Asia. J. Thorac. Dis. 2015, 7, 376-385. [CrossRef] [PubMed]

119. Almohammed, R.A.; Bird, E.L. Public knowledge and behaviours relating to antibiotic use in Gulf Cooperation Council countries: A systematic review. J. Infect. Public Health 2019, 12, 159-166. [CrossRef]

120. Al Baz, M.; Law, M.R.; Saadeh, R. Antibiotics use among Palestine refugees attending UNRWA primary health care centers in Jordan-A cross-sectional study. Travel Med. Infect. Dis. 2018, 22, 25-29. [CrossRef]

121. Barah, F.; Goncalves, V. Antibiotic use and knowledge in the community in Kalamoon, Syrian Arab Republic: A cross-sectional study. East. Mediterr. Health J. 2010, 16, 516-521. [CrossRef]

122. Albawani, S.; Gnanasan, S.; Abd, A.N.; Hassan, Y. Self-Medication with Antibiotics in Children in Sana'a City, Yemen. Oman Med. J. 2010, 25, 41-43. [CrossRef]

Publisher's Note: MDPI stays neutral with regard to jurisdictional claims in published maps and institutional affiliations.

(C) 2020 by the authors. Licensee MDPI, Basel, Switzerland. This article is an open access article distributed under the terms and conditions of the Creative Commons Attribution (CC BY) license (http://creativecommons.org/licenses/by/4.0/). 